\title{
In-situ TEM study of irradiation-induced damage mechanisms in monoclinic- $\mathrm{ZrO}_{2}$ Junliang Liu ${ }^{1 *}$, Anamul Haq Mir², Guanze He ${ }^{1}$, Mohsen Danaie ${ }^{3}$, Jonathan Hinks², Stephen Donnelly ${ }^{2}$, Heidi Nordin ${ }^{4}$, Sergio Lozano-Perez ${ }^{1}$, Chris R. M. Grovenor ${ }^{1}$ \\ ${ }^{1}$ Department of Materials, University of Oxford, UK. \\ ${ }^{2}$ MIAMI Facility, School of Computing and Engineering, University of Huddersfield, UK. 3electron Physical Science Imaging Centre, Diamond Light Source, UK. \\ ${ }^{4}$ Canadian Nuclear Laboratories, Chalk River, Canada. \\ *Corresponding author: junliang.liu@materials.ox.ac.uk
}

\begin{abstract}
We have investigated the microstructural and crystallographic evolution of nanocrystalline zirconia under heavy ion irradiation using in-situ transmission electron microscopy (TEM) and have studied the atomic configurations of defect clusters using aberration-corrected scanning transmission electron microscopy (STEM). Under heavy ion irradiation the monoclinic- $\mathrm{ZrO}_{2}$ is observed to transform into cubic phase, stabilised by the strain induced by irradiationinduced defect clusters. We suggest that the monoclinic-to-cubic transformation is martensitic in nature with an orientation relationship identified to be $(100)_{m} \|(100)_{c}$ and $[001]_{\mathrm{m}} \|[001]_{\mathrm{c}}$. By increasing the damage dose, both the formation of voids and irradiationinduced grain growth were observed. A model for the formation of voids is proposed, taking defect interactions into consideration. The study has also demonstrated that high resolution orientation mapping by transmission Kikuchi diffraction (TKD) combined with in-situ irradiation in a TEM is a powerful method to probe the mechanisms controlling irradiationinduced processes, including grain boundary migration, phase transformations and texture evolution.
\end{abstract}

Keywords: Irradiation damage; Grain growth; In-situ transmission electron microscopy (TEM); transmission Kikuchi diffraction (TKD). 


\section{Introduction}

Zirconium dioxide (zirconia, $\mathrm{ZrO}_{2}$ ) displays three distinct polymorphs; a high-temperature cubic phase $\left(\mathrm{c}-\mathrm{ZrO}_{2}\right)$, an intermediate temperature tetragonal phase $\left(\mathrm{t}-\mathrm{ZrO}_{2}\right)$ and a low temperature monoclinic phase $\left(\mathrm{m}-\mathrm{ZrO}_{2}\right)$. Because of its resistance to radiation damage, zirconia has been proposed as a containment material for radioactive waste [1], a potential inert-matrix, nuclear fuel-form for the transmutation burning of surplus plutonium and minor actinides [2], and the monoclinic phase is the major product of the corrosion of the zirconium alloys used as nuclear fuel cladding. The microstructure of these oxide scales plays an important role in controlling the corrosion and hydrogen pickup performance of cladding materials in pressurized water nuclear reactors [3,4]. Because it is found in these safetycritical applications in the nuclear industry, it is important to understand the response of zirconia to irradiation, and how any microstructural changes induced by irradiation can influence the properties of the zirconium oxide as a containment material or corrosion protection layer. In light water reactor (LWR) $\cup_{2}$ fuels, highly energetic fission fragments like ${ }^{60} \mathrm{Co},{ }^{85} \mathrm{Kr}$ and ${ }^{106} \mathrm{Ru}$ are created from the decay processes of ${ }^{235} \mathrm{U}$ [5], and so oxides formed on the inner surface of the cladding are exposed to a high flux of energetic fission fragments as well as irradiation with neutrons. Thus it is important to consider damage created by heavy ion irradiation as well as the more often studied neutron damage processes.

\subsection{Defect evolution under irradiation}

Under irradiation, neutral vacancies and interstitials are created as Frenkel pairs in metals, but in ceramic materials more complex charged vacancies and interstitials can be produced; including Schottky pairs and both cation $\left(\mathrm{Zr}_{\mathrm{i}}^{\cdots}\right.$ and $\left.\mathrm{V}_{\mathrm{Zr}}^{\prime \prime \prime}\right)$ and anion $\left(\mathrm{O}_{\mathrm{i}}^{\prime \prime}\right.$ and $\left.\mathrm{V}_{\mathrm{O}}^{\prime \prime}\right)$ Frenkel pairs [6]. The microstructural evolution of ceramic materials under irradiation has also been widely reported [7], and some materials share common features with metallic alloys including the formation of defect clusters and voids, grain growth and damage-induced phase transformations. Although a substantial fraction of the point defects generated by radiation damage in solid materials may recombine immediately, the remaining defects are the key to understanding the irradiation-induced effects. Calculations on oxide materials with the fluorite structure such as $\mathrm{UO}_{2}, \mathrm{ZrO}_{2}$ and $\mathrm{CeO}_{2}$ predict that the oxygen defects have significantly lower migration barrier energies and hence higher mobilities than cation defects 
$[8,9]$. For instance, the migration energies in $\mathrm{c}-\mathrm{ZrO}_{2}$ calculated by Aidhy et al. [9] for $\mathrm{Zr}_{\mathrm{i}} \mathrm{i}^{\prime \cdots}, \mathrm{V}_{\mathrm{Zr}}^{\mathrm{\prime \prime}}$, $\mathrm{O}_{\mathrm{i}}^{\prime \prime}$ and $\mathrm{V}_{\mathrm{O}}$ are $5.9 \mathrm{eV}, 6.2 \mathrm{eV}, 0.7 \mathrm{eV}$ and $0.3 \mathrm{eV}$, respectively. Similar modelling results suggest that a system with completely separated vacancies has very high energy and is not stable [6], and as a result the formation of Schottky defects is favoured [10] by the diffusion of mobile anion vacancies to the less-mobile cation vacancies. There have been extensive modelling studies on the evolution of point defects in zirconia [9-15], but much less experimental work has been done, probably because the point defects in zirconia exist preferentially in very small clusters [16] that are very challenging to detect by conventional microscopy techniques. Positron annihilation lifetime spectroscopy (PALS) has been shown useful to study vacancytype clusters in zirconia $[15,17]$, but integrate information from a relatively large volume and cannot give local information on the atomic configurations of defects and their clusters, which will require the application of advanced electron microscopies.

Both simulations [18] and experimental studies [19] show that grain boundaries are effective sinks for irradiation-induced defects in metallic and oxide materials. When the grain size approaches the mean diffusion distance of defects created during the cascade events, the role of grain boundaries in the alleviation of radiation damage becomes significant as more defects will be absorbed by these sinks. Irradiation-induced grain growth behaviour has previously been reported in nanocrystalline $\mathrm{c}-\mathrm{ZrO}_{2}$ [20], and described as a defect-driven mechanism resulting from the absorption of these defects near the grain boundaries.

\subsection{Phase transformations and stabilisation mechanisms under irradiation}

Irradiation-induced phase transformations in $\mathrm{m}-\mathrm{ZrO}_{2}$ have been extensively reported. A monoclinic-to-tetragonal transformation under ion irradiation has been described by some authors [21-24], while others claim that the transformation is monoclinic-to-cubic [25-28], and some [29] report that a crystallographic transformation has occurred without confirming the nature of the product. Both the monoclinic-to-cubic and the monoclinic-to-tetragonal transformations (or inverse transformations) result in a significant change of the unit cell volume ( $6 \%$ for the monoclinic-to-tetragonal transformation and $\sim 5 \%$ for the monoclinic-tocubic transformation [30]), and in the nanostructured corrosion products formed on zirconium alloys in a nuclear environment this can lead to oxide cracking and degrade the overall corrosion performance of these materials [4, 31]. A fundamental understanding of phase transformations and the stabilization of metastable phases of zirconia under irradiation 
is thus important to derive reliable models of the corrosion behaviour of zirconium alloys in service.

The tetragonal and cubic phases are metastable at room temperature, but both modelling and experimental results suggest that these phases can be stabilized by oxygen vacancies [32, $33]$, stress [34, 35] and cation dopants [36, 37]. The obvious question is which are the dominant mechanism(s) that may stabilise these metastable phases under the conditions experienced in service. From modelling studies, Fabris et al. [32] and Raza et al. [33] have shown that oxygen vacancies alone can stabilise the cubic phase at room temperature without the need for any cation doping. Anionic point defects generate stronger strain fields than $\mathrm{Zr}$ point defects [38], and the structural distortions around oxygen vacancies can affect the relative stability of the cubic phase $[39,40]$. Incorporating oxygen vacancies at concentrations as low as 3 at\% is predicted to stabilize the high-temperature cubic phase at room temperature [33]. An attempt to quantify the concentration of defects in irradiated zirconia using molecular dynamics simulations [41] predicted that a $30 \mathrm{keV} \mathrm{Zr}$ recoil can create 0.0016 displacements per atom ( $\mathrm{dpa}$ ) and $~ 0.08$ at\% of both interstitials and vacancies in the cascade. Most of these irradiation-induced vacancies will recombine with interstitials and rapidly annihilate, but a steady state of $~ 0.002$ at $\%$ vacancies ( $40 \%$ cation vacancies and $60 \%$ anion vacancies) after the relaxation of a cascade has been proposed [41]. If we assume that the concentration of vacancies at steady state increases linearly with the damage level, a concentration of 3 at\% oxygen vacancies can be achieved at $3 \mathrm{dpa}$, well within the damage levels that can be reached in service (and also easy to simulate using in-situ irradiation experiments). An experimental study on the effect of $O$ vacancies on the stability of zirconia also suggested that a decrease in $O$ vacancy concentration decreased the stability of metastable tetragonal zirconia, and promoted its transformation into the monoclinic phase [42].

An additional factor to consider is the effect of stress/strain induced in an oxide matrix by irradiation defects and their clusters. Experimental evidence showing the stress-stabilization of the tetragonal phase has been extensively reported in oxides formed on zirconium alloys $[34,35,43]$, so that the tetragonal phase is concentrated at the metal-oxide interface where the highest levels of compressive stress are generated. Moll et al. [44] have measured irradiation-induced strain as a function of fluence in $\mathrm{c}-\mathrm{ZrO}_{2}$ irradiated by $4 \mathrm{MeV} \mathrm{Au}$ ions, and 
shown that the small defect clusters formed in the low dose regime $\left(<10^{15}\right.$ ions.cm $\left.{ }^{-2}\right)$ can lead to a sharp increase (up to $0.5 \%$ ) in elastic strain. Using $940 \mathrm{MeV} \mathrm{Pb}$ ions to irradiate $\mathrm{c}-\mathrm{ZrO}_{2}$, Sattonnay et. al. [45] reported the hydrostatic stress increases from 80 to $460 \mathrm{MPa}$ when the fluence is increased from $5 \times 10^{11}$ to $4 \times 10^{13}$ ions. $\mathrm{cm}^{-2}$. The local stress/strain buildup during irradiation may also contribute to the stabilization of any irradiation-induced metastable phases [46].

The stabilization of $\mathrm{t}-$ and $\mathrm{c}-\mathrm{ZrO}_{2}$ phases by using substitutional cation dopants such as $\mathrm{CaO}$, $\mathrm{MgO}$ and $\mathrm{Y}_{2} \mathrm{O}_{3}$ has been extensively studied [47-49] and the mechanisms are well understood. Common nuclear cladding $\mathrm{Zr}$ alloys contain 97-99\% zirconium, with additional minor additions of alloying elements like $\mathrm{Sn}, \mathrm{Nb}, \mathrm{Fe}$ and $\mathrm{Cr}$ added to optimize the desired corrosion and mechanical properties. Though some of these alloying elements can act as cation dopants in zirconium oxides [50], their contribution to stabilizing the metastable phases should be rather limited due to their low concentrations, and this mechanism will not be discussed further here.

\subsection{Motivations for this study}

Compared to the large body of modelling work on microstructural evolution of zirconia under irradiation, detailed experimental characterization of damage processes, especially at the atomic scale, are rarely reported. The objectives of this study were to;

1. follow dynamically (in-situ) the evolution of irradiation-induced defect clusters in oxide scales on commercial $\mathrm{Zr}$ fuel cladding alloys, and to reveal their atomic configurations.

2. follow in-situ irradiation-induced phase transformations and grain growth as a function of irradiation fluence, to reveal the nature of phase transformation products, and to discuss the mechanisms stabilising metastable phases under irradiation.

3. discuss the effect of the irradiation-induced microstructural evolution of these oxide scales on the in-service performance of zirconium alloys.

Realization of these research goals relies heavily on microstructural characterization using state-of-art microscopies. We have combined in-situ ion irradiation in a transmission electron microscope (TEM) with transmission Kikuchi diffraction (TKD), atomic-resolution scanning transmission electron microscope (STEM) and high-resolution energy dispersive X-ray (EDX) 
to characterize irradiation-induced microstructural evolution in a nanocrystalline zirconium oxide formed by aqueous corrosion of a $\mathrm{Zr}-\mathrm{Nb}$ nuclear fuel cladding alloy. This work also involved the development of new sample preparation methodologies to provide greater sample stability and enable analysis by this range of microscopy techniques.

\section{Experimental procedures}

\subsection{Materials and sample preparation}

The samples used in this study were prepared from a Westinghouse $\mathrm{Zr}-0.5 \mathrm{Nb}$ model alloy provided as a tube in the recrystallized condition. The material was corroded in an autoclave filled with pure water at $360^{\circ} \mathrm{C}$ and $18 \mathrm{MPa}$ for 210 days to form an oxide of thickness approximately $3 \mu \mathrm{m}$. Cross-sectional electron transparent foils containing both the oxide layer and the metal matrix were prepared using the Focused Ion Beam (FIB) method on a Zeiss Crossbeam 540 system with an initial milling current of 7000-300 pA at $30 \mathrm{kV}$. Recent studies have shown that the bombardment of $\mathrm{FIB} \mathrm{Ga}^{+}$ions can also induce the monoclinic to tetragonal phase transformation in zirconia especially when the beam energy is higher than $5 \mathrm{kV}$ [51]. To reduce any surface damage induced by the milling processes at $30 \mathrm{kV}$, glancing incidence FIB polishing was performed at $5 \mathrm{kV}, 200 \mathrm{pA}$ and $10^{\circ}$ incident angle as suggested by $[51,52]$ and to a uniform sample thickness of $\sim 50 \mathrm{~nm}$. It is important to achieve samples as thin as this in order to get analysable Kikuchi patterns from TKD analysis of nanocrystalline materials [53]. Specimens for in-situ ion irradiation experiments were prepared using an improved strategy to avoid irradiation-induced specimen bending at high damage levels. A detailed description of this sample preparation methodology can be found in the supplementary information. Figure 1 shows an example of a TEM foil prepared following these procedures. The improved specimen geometry stability allows a single specimen to be transported without risk of damage, and to be characterized by a combination of techniques, in-situ TEM, STEM/EDX, TKD and even NanoSIMS [54], to correlate observations of dynamic irradiation-damage processes with the irradiation-induced evolution of local crystallographic orientation and micro-chemistry in exactly the same region. 


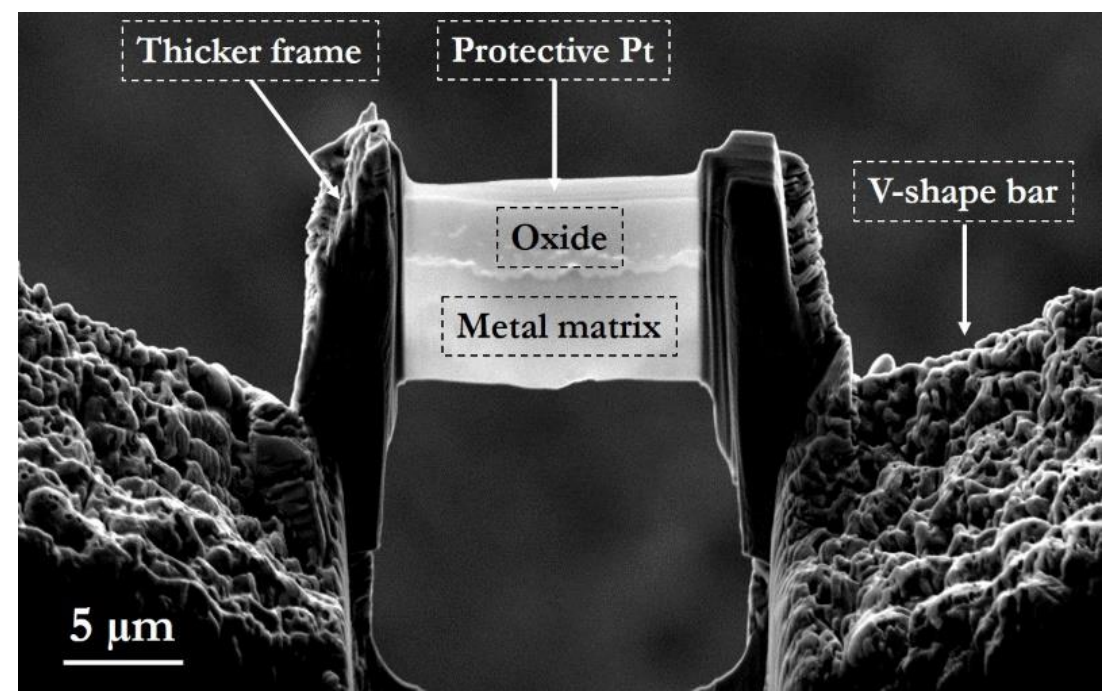

Figure 1 SEM secondary electron image at $5 \mathrm{kV}$ showing an example of a thin TEM specimen containing both zirconium oxide and metal matrix prepared using FIB to have improved mechanical robustness.

To compare irradiation-induced effects in corrosion scales on similar alloys by heavy ions and by neutrons, we have also prepared and characterised TEM foils containing the oxide layers

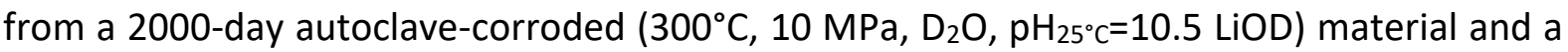
sample that has been exposed in the Halden test reactor for 2700 days $\left(10^{22} \mathrm{n} . \mathrm{cm}^{-2}, \sim 8 \mathrm{dpa}\right.$ in the top part of the oxide, $\left.325^{\circ} \mathrm{C}, 10 \mathrm{MPa}, \mathrm{D}_{2} \mathrm{O}, \mathrm{pH}_{25^{\circ} \mathrm{C}}=10.5 \mathrm{LiOD}\right)$. Both of these samples are $\mathrm{Zr}-2.5 \mathrm{Nb}$ cladding materials provided by Canadian Nuclear Laboratories (CNL).

\subsection{In-situ irradiation in the transmission electron microscope}

In-situ irradiation experiments were conducted at the University of Huddersfield on the Microscope and Ion Accelerator for Materials Investigation (MIAMI) facility [55] using $700 \mathrm{keV}$ $\mathrm{Kr}^{2+}$ ions up to a fluence of $1.9 \times 10^{16}$ ions. $\mathrm{cm}^{-2}$ at a rate of $1-5 \times 10^{12}$ ions. $\mathrm{cm}^{-2} . \mathrm{s}^{-1}$ at room temperature. The damage rate in terms of displacement per atom per second $\left(\mathrm{dpa} . \mathrm{s}^{-1}\right)$ and the residual $\mathrm{Kr}$ concentration was estimated using SRIM 2013 [56] by simulating 999,999 incident ions, selecting the Kinchin-Pease damage cascade mode and displacement energies set to $80 \mathrm{eV}$ and $120 \mathrm{eV}$ for $\mathrm{Zr}$ and $\mathrm{O}$ according to experimental measurements in [57]. More details about SRIM settings can be found in supplementary information and Figure S2. The calculated dpa rate is $\sim 0.0005-0.0025$ dpa.s $\mathrm{s}^{-1}\left(\sim 1-5 \times 10^{12}\right.$ ions. $\left.\mathrm{cm}^{-2} \cdot \mathrm{s}^{-1}\right)$, and the average residual $\mathrm{Kr}$ concentration in the thin foil is estimated to be $\sim 0.05$ at\% at a fluence of $1.9 \times 10^{16}$ ions. $\mathrm{cm}^{-2}$. The nuclear and electron stopping powers calculated by SRIM are $0.7 \mathrm{keV} . \mathrm{nm}^{-1}$ and 
$0.3 \mathrm{keV} \cdot \mathrm{nm}^{-1}$, respectively, and the detailed damage profile and $\mathrm{Kr}$ concentration distribution calculated by SRIM for the maximum fluence used here are shown in Figure 2.

$\mathrm{Kr}$ and $\mathrm{Xe}$ are two of the most abundant gaseous fission products created in $\mathrm{LWR} \mathrm{UO}_{2}$ fuels, with a total yield of around 0.3 atoms/fission [58]. The mean kinetic energies of $\mathrm{Kr}$ and $\mathrm{Xe}$ created during fission events are of the order of $100 \mathrm{MeV} /$ atom [59]. In the fuel the kinetic energy of these species is lost primarily via electron excitations, and most of the atoms/ions will form gas bubbles within the fuel matrix. However some will escape into the fuel-tocladding gap [58], leading to the implantation of $\mathrm{Kr}$ and $\mathrm{Xe}$ with a wide range of kinetic energies from a few $\mathrm{eV}$ to tens of $\mathrm{MeV}$ into the inner cladding surface.

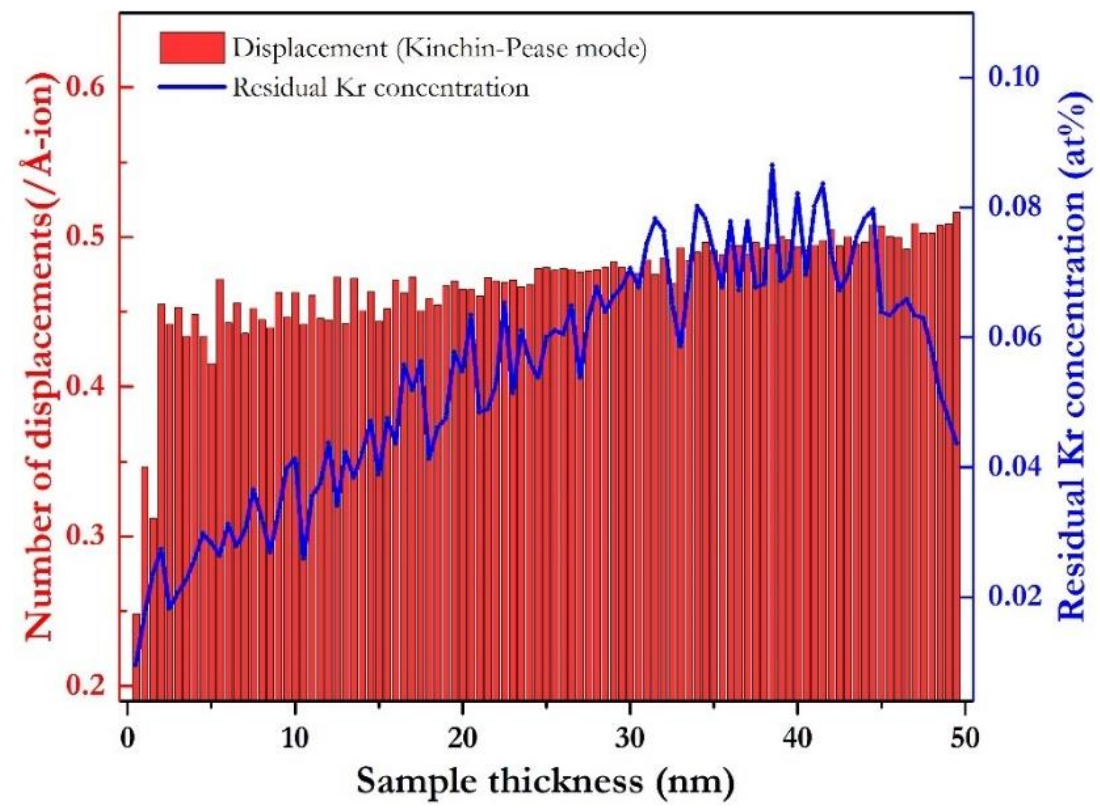

Figure 2 Damage profile and residual $\mathrm{Kr}$ concentration in the sample calculated by SRIM for a fluence of $1.9 \times 10^{16}$ ions. $\mathrm{cm}^{-2}$.

Cavities such as voids and bubbles can be easily imaged using Fresnel contrast in the conventional TEM in bright-field mode [60] and this contrast originates from the difference in the inner potential of the matrix and the cavity and depends on effective thickness variations in the direction of the incident electron beam. Contrast of Fresnel fringes around the periphery of a cavity is inverted on over- and under-focused images which was used to characterise the irradiation induced bubbles/voids during in-situ irradiation.

In-situ TEM is a powerful tool in determining the underlying mechanism governing the evolution of defects and microstructure in materials in real time. However, it is very timeconsuming to extract from in-situ TEM images statistical information on grain size, phase 
fractions and crystalline orientations. To help overcome this problem, we have combined insitu irradiation in TEM with TKD. To reduce any surface roughness and contamination induced during the in-situ irradiation processes, both surfaces of in-situ irradiated foils were polished using glancing incidence FIB at $5 \mathrm{kV}, 200 \mathrm{pA}$ and $10^{\circ}$ incident angle for a few seconds before TKD and STEM analysis.

\subsection{Transmission Kikuchi diffraction}

The recently developed on-axis TKD technique has been demonstrated to have the capability to generate simultaneously high resolution results on grain morphology and crystal orientation [61]. By using an electron-transparent thin TEM foil instead of a bulk sample, the lateral resolution of TKD can be improved to $\sim 3 \mathrm{~nm}$, making this technique particularly suitable for the study of the phase distribution and crystallography of complex nano-scale materials [62]. In this study, we have tracked the crystal orientation and phase evolution under irradiation by analysing the same regions before and after irradiation. Due to the surface sensitivity nature of TKD analysis, which can lead to different grain structures even on the same specimen when opposite sides of a TEM foil are facing the incident electron beam [53], care has been taken to ensure the same side of a specimen was analysed on both occasions.

TKD characterization was carried out on a Zeiss Merlin FEG-SEM system equipped with a Bruker OPTIMUS TM TKD head and an e-flash high resolution Electron Backscatter Diffraction (EBSD) detector. More information about the TKD configurations can be found in [63]. The accelerating voltage was set to $30 \mathrm{kV}$ and a probe current of $1.5 \mathrm{nA}$ used to acquire Kikuchi patterns with resolution $320 \times 200$ using a pixel time of $9.3 \mathrm{~ms}$. A step size of $5 \mathrm{~nm}$ was used to enable the characterisation of nano-crystalline grains. Consistent mapping parameters were used for all the maps to avoid artefacts that can be induced by changing imaging conditions. All the TKD maps were further cleaned using the Oxford Instruments HKL Channel 5 software package to remove isolated pixels that were incorrectly indexed or not solved. The crystallographic information used in identifying the phase distribution in the samples is summarized in Table S1 in the supplementary information. 


\subsection{Transmission electron microscopy (TEM)}

Post-irradiation specimens were characterised using TEM and STEM to identify crystallographic features. TEM bright field (BF) observations and selected area diffraction (SAD) was performed using a JEOL JEM-3000F operating at $300 \mathrm{kV}$. Energy dispersive X-ray (EDX) spectra to identify the nano-chemistry of defect clusters were acquired on a JEOL JEMARM200F STEM operated at $200 \mathrm{kV}$ with a convergence angle of $30 \mathrm{mrad}$ and a collection angle of $40 \mathrm{mrad}$. The average thickness of the region of interest was measured using the $t / \lambda$ method suggested by Malis et. al. [64], and in the bulk oxide regions is $49 \pm 5 \mathrm{~nm}$, while the edges of the cracks always found in these corrosion scales are thinner at $15 \pm 2 \mathrm{~nm}$.

High-angle annular dark-field (HAADF) scanning transmission electron microscopy can image individual atoms at an atomic resolution [65]. At high angles the dominant signal is from Rutherford scattering and the intensity of each pixel in the image will be proportional to $t \rho Z^{2}$, where $t$ is the foil thickness, $\rho$ is the density and $Z$ is the average atomic number [66]. When applied in a restricted zone-axis orientation, the HAADF image can reveal the atomic structure of defect clusters from the $Z$ contrast. Atomic-resolution HAADF-STEM imaging was carried on an aberration-corrected JEOL JEM-ARM300F STEM at the electron Physical Science Imaging Centre (ePSIC) at the Diamond Light Source with an ultra-high spatial resolution of approximately $0.55 \AA$ using $300 \mathrm{kV}$ accelerating voltage and $9 \mathrm{~cm}$ camera length (the HAADF detector collection angle is between 77 and 209 mrad). HAADF images were noise-filtered using a lattice enhanced filter without removing background [67]. A comparison between the raw and filtered images can be found in supplementary Figure S3. Geometric phase analysis (GPA) [68] of atomic-resolution HAADF-STEM images was performed to reveal the strain distribution around defect clusters using an open source program Strain++ (https://iippeters.github.io/Strainpp/).

\section{Experimental Results}

\subsection{In-situ observation of irradiation-induced phase transformation}

In this study, the zirconium oxides grown by autoclave corrosion were observed to have a high resistance to irradiation-induced amorphisation up to a fluence of $1.9 \times 10^{16}$ ions. $\mathrm{cm}^{-2}$ at $10^{12}$ ions. $\mathrm{cm}^{-2} . \mathrm{s}^{-1}$, but a gradual evolution of microstructure in the bulk oxide can be seen in 
long term in-situ irradiation experiments as shown in Figure 3. Strong diffraction contrast can be seen in the pre-irradiation sample, Figure 3 (a), arising from the characteristic nanocrystalline grain structure in a corrosion scale grown under simulated reactor conditions, and the complex SAD patterns are also characteristic of the textured zirconium oxide layer $[69,70]$. The diffraction contrast in the bright-field micrographs gradually changed under irradiation and we observed fewer but brighter spots in the diffraction patterns. Indications of localized grain growth in the oxide under irradiation were observed in the in-situ TEM images, but the areas examined are small and grain boundaries in some regions are no longer discernible, so no conclusive results on the change in microstructure could be obtained from this kind of images.
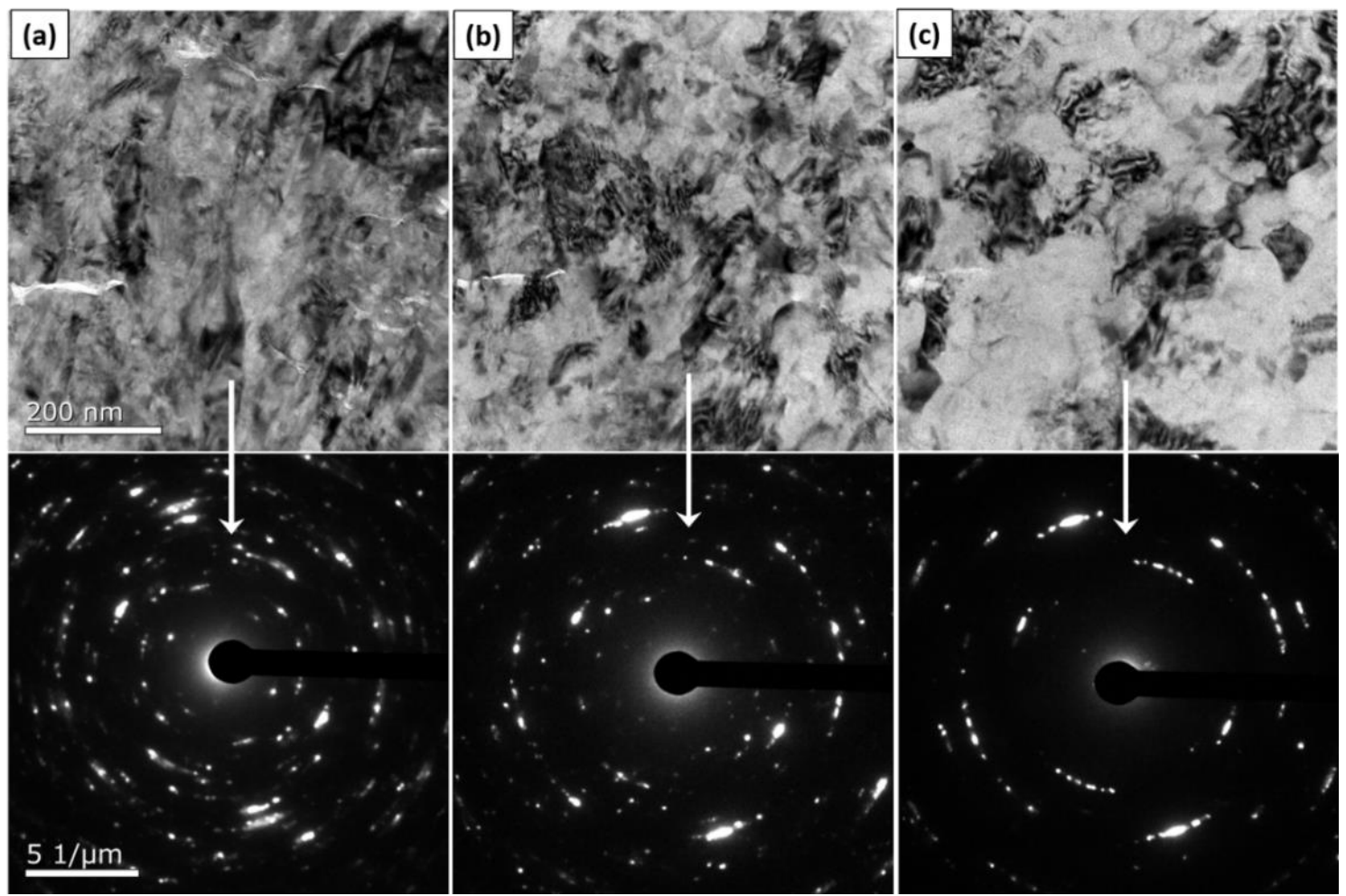

Figure 3 Bright-field TEM images and corresponding selected area diffraction (SAD) patterns showing the microstructural evolution of the oxide under $700 \mathrm{keV} \mathrm{Kr}^{2+}$ irradiation: (a) $0 \mathrm{dpa}$, (b) $3 \mathrm{dpa}, 5.6 \times 10^{15}$ ions. $\mathrm{cm}^{-2}$ and (c) $10 \mathrm{dpa}, 1.9 \times 10^{16}$ ions.cm ${ }^{-2}$.

Irradiation-induced phase transformations can be studied from the evolution of diffraction patterns like those shown in Figure 3. However, these patterns are formed by diffraction from only a limited number of individual small oxide grains and, especially when there is strong crystallographic texture [71], can be difficult to interpret. To make them easier to index, the patterns were rotationally averaged using the Difftool developed by Michell [72], which 
transforms the two-dimensional electron diffraction pattern into a one-dimensional profile similar to a normal X-ray diffraction pattern, Figure 4. The background in these diffraction profiles was subsequently removed using the OriginPro software package. For ease of comparison, simulated diffraction patterns are also shown in Figure 4 (a) for $\mathrm{m}-\mathrm{ZrO}_{2}, \mathrm{t}-\mathrm{ZrO}_{2}$ and $\mathrm{c}-\mathrm{ZrO}_{2}$, generated using the CrystalMaker and CrystaDiffract software packages using the standard lattice parameters summarized in Table S1 in the supplementary information. Indexing and interpretation of the experimental SAD patterns can then be conducted through a direct comparison with the simulated diffraction profiles.

Typical rotationally averaged in-situ diffraction patterns acquired at different damage levels are presented in Figure 4 (b). As we would expect, the pre-irradiation profile matches well with the pattern simulated for $\mathrm{m}-\mathrm{ZrO}_{2}$, in agreement with previous studies showing that more than $97 \%$ of the oxide in thin TEM lamella lifted out from oxides formed on water-corroded $\mathrm{Zr}$ alloys is monoclinic $[62,71]$. Some peaks from the monoclinic phase are missing in the experimental spectrum as a result of the strong oxide texture. At $3 \mathrm{dpa}$, some of the strong peaks from the monoclinic phase, e.g. $(011)_{\mathrm{m}}$ and $(112)_{\mathrm{m}}$, decrease in intensity, and after 10 dpa all the peaks characteristic of the monoclinic phase have disappeared, Figure 4 (b), indicating that the monoclinic phase has transformed wholly into another phase. 
(a) Simulated diffraction patterns from the different polymorphs of $\mathrm{ZrO}_{2}$

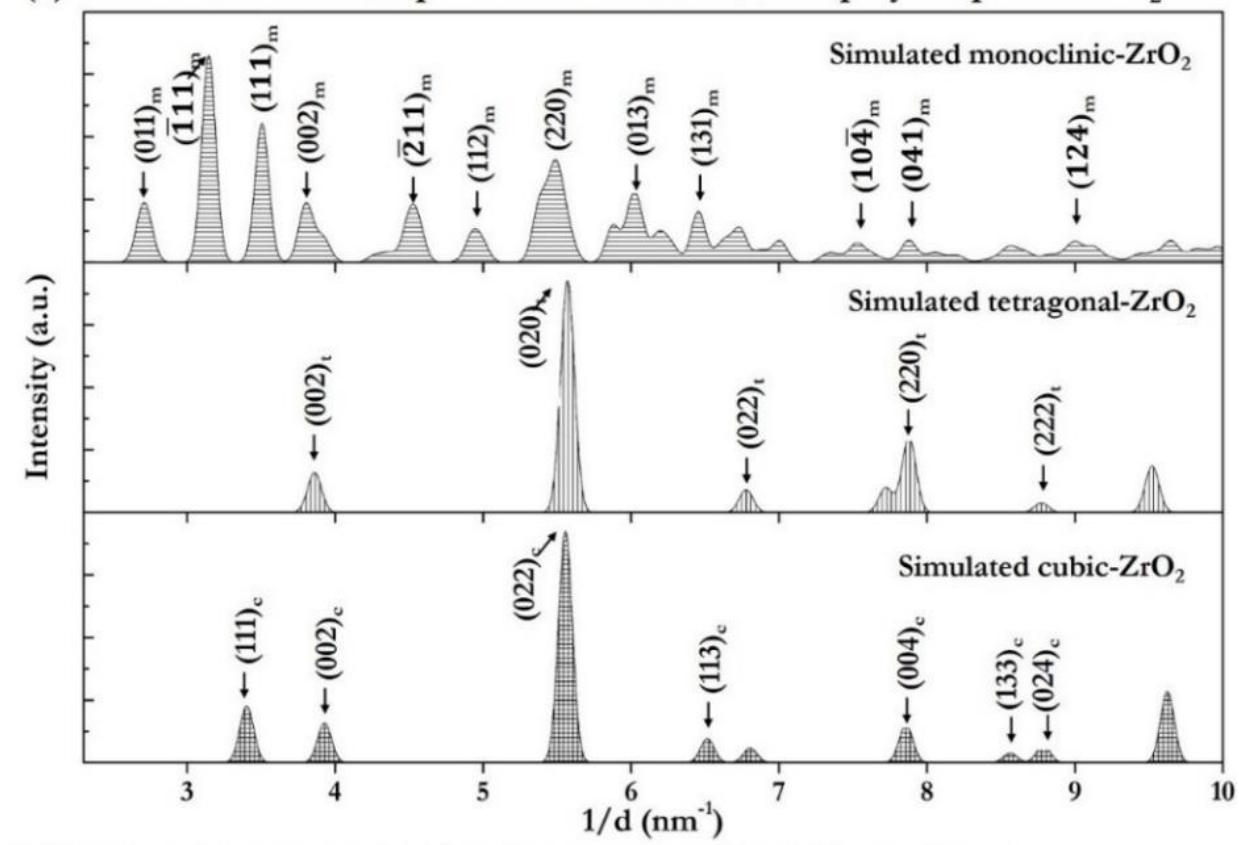

(b) Rotationally averaged diffraction patterns after different ion doses

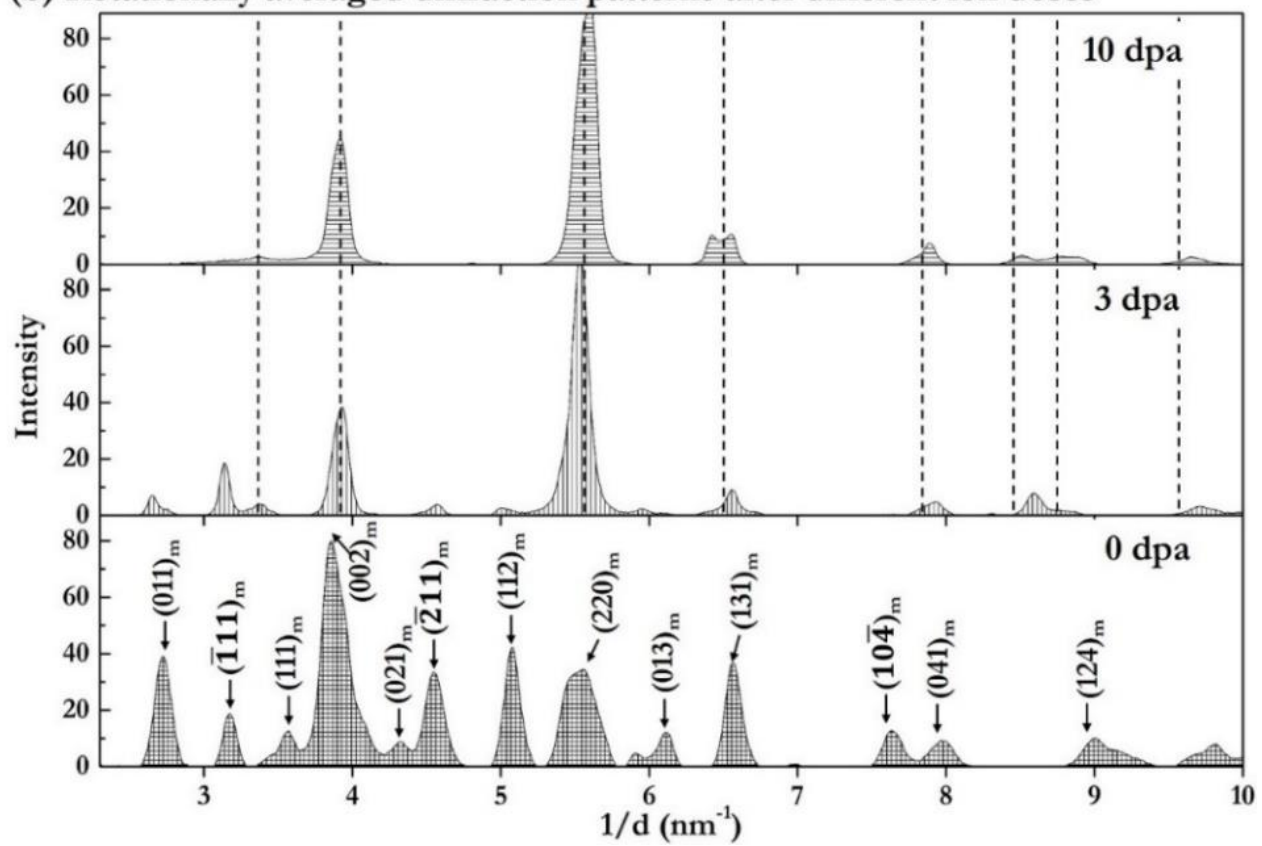

Figure 4 (a) Simulated electron diffraction profiles from different polymorphs of $\mathrm{ZrO}_{2}$. (b) Rotationally averaged experimental diffraction patterns from specimens irradiated by 700 $\mathrm{keV} \mathrm{Kr}^{2+}$ at room temperature to different damage levels - from top to bottom: preirradiation ( $0 \mathrm{dpa}), 5.6 \times 10^{15}$ ions.cm ${ }^{-2}(3 \mathrm{dpa})$ and (c) $1.9 \times 10^{16}$ ions.cm ${ }^{-2}(10 \mathrm{dpa})$.

Due to the similarity between the crystal structures of $\mathrm{t}-\mathrm{ZrO}_{2}$ and $\mathrm{c}-\mathrm{ZrO}_{2}$ [73], it is challenging to determine the crystalline nature of the product phase using this SAD data, as can be seen in Figure 4 (a) with several peaks overlapping. The evolution in diffraction peak intensity is clearly dependent on damage dose, as shown in Figure 4 (b), but it is hard from this SAD data to extract quantitative values for the fractions of the different phases because factors such as 
variations in electron beam illumination intensity and sample bending can also induce changes in relative peak intensity. We have thus used TKD analysis, with its higher angular resolution $[74,75]$ on these ion-irradiated samples to generate statistically significant information simultaneously on grain morphology, crystallographic phase and orientation.

\subsection{Phase identification and grain size evolution under irradiation}

Figure 5 shows pattern quality and phase maps of specimens in-situ irradiated to different doses at room temperature. The crystal structure information used here for TKD indexing (see Table S1 in the supplementary information) is the same as for SAD indexing. In the preirradiation oxide film, most of the small aligned columnar grains are found to be $\mathrm{m}-\mathrm{ZrO}_{2}$, and a small volume fraction ( $2.5 \%)$ of $\mathrm{t}-\mathrm{ZrO}_{2}$ grains are found scattered throughout the oxide as expected $[62,71]$, Figure 5 (a) and (d). This tetragonal phase fraction is significantly lower than reported by bulk measurements by X-ray diffraction analysis where studies of oxide layers formed on similar alloys reported the tetragonal phase fraction to lie in the range 3$15 \%[34,76]$. The non-destructive nature of these measurements should preserve the stress state in the oxide, while stress relaxation is expected to occur during the preparation of thin TEM samples which allows relaxation of some of the stress-stabilized tetragonal grains into the equilibrium monoclinic phase [35]. Significantly, the phases in this pre-irradiation specimen are indexed with high confidence as monoclinic and tetragonal (not cubic) in agreement with previous studies $[62,77]$.

Both the grain morphology and the phase distribution are observed to change substantially under irradiation, and the volume fractions of indexed oxide phases at different doses are summarized in Table 1 . After $4 \mathrm{dpa}$, the majority of the oxide film has already transformed into the cubic phase and only a few surviving $\mathrm{m}-\mathrm{ZrO}_{2}$ grains can be seen, Figure 5 (e). After 10 $\mathrm{dpa}$ the volume fraction of surviving $\mathrm{m}-\mathrm{ZrO}_{2}$ is $0.4 \%$. A similar fraction of tetragonal phase is observed in both the $4 \mathrm{dpa}$ and $10 \mathrm{dpa}$ specimens but, instead of being observed as clearly identified small grains like those in the pre-irradiation oxide, the pixels identified as a tetragonal phase in the post-irradiation maps shown in Figure $5(e)$ and (f), are mostly isolated at the grain boundaries- possibly as a result of pattern overlap and mis-indexing. After $4 \mathrm{dpa}$, many small grains can still be seen in the regions containing a mixture of $\mathrm{c}-\mathrm{ZrO}_{2}$ and untransformed $\mathrm{m}-\mathrm{ZrO}_{2}$, but after $10 \mathrm{dpa}$ the average $\mathrm{c}-\mathrm{ZrO}_{2}$ grain size has increased quite significantly as shown by comparing Figure 5 (b) and (c). This kind of irradiation-induced grain 
growth behaviour has previously been reported in nanocrystalline c- $\mathrm{ZrO}_{2}$ [20], and has been described as a defect-driven mechanism resulting from the absorption of the cascade defects near the grain boundaries. From these observations we conclude that the monoclinic-to-cubic transformation occurs in the early stages of irradiation, with the nucleation initially of small cubic grains and once the monoclinic to cubic transformation is complete then grain growth can proceed.

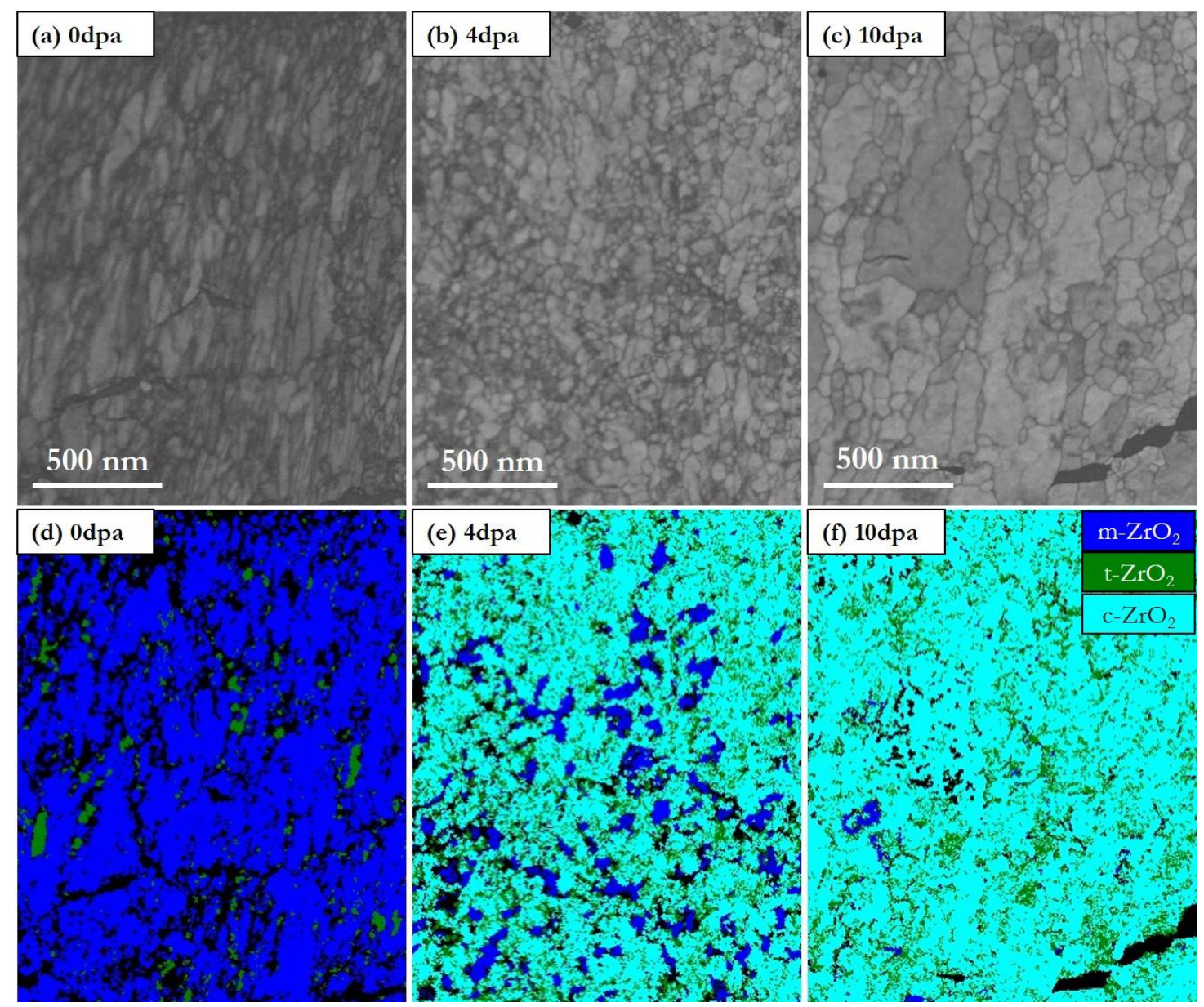

Figure 5 TKD pattern quality and phase maps from typical regions of in-situ irradiated $\mathrm{Zr}$ oxide specimens. ( $a$ and d) $0 \mathrm{dpa}$, (b and e) $4 \mathrm{dpa}, 7.4 \times 10^{15}$ ions. $\mathrm{cm}^{-2}$ and (c and f) $10 \mathrm{dpa}$, $1.9 \times 10^{16}$ ions. $\mathrm{cm}^{-2}$.

Table 1 TKD indexed phase fractions and grain size measured at different damage levels

\begin{tabular}{lccc}
\hline & $0 \mathrm{dpa}$ & $4 \mathrm{dpa}$ & $10 \mathrm{dpa}$ \\
\hline Monoclinic & $97.5 \%$ & $10.5 \%$ & $0.4 \%$ \\
Tetragonal & $2.5 \%$ & $4.1 \%$ & $4.4 \%$ \\
Cubic & 0 & $85.4 \%$ & $95.2 \%$ \\
\hline Horizontal grain size $(\mathrm{nm})$ & $63 \pm 6$ & $66 \pm 11$ & $100 \pm 20$ \\
Vertical grain size $(\mathrm{nm})$ & $140 \pm 30$ & $76 \pm 13$ & $160 \pm 50$ \\
Aspect ratio (vertical/horizontal) & 2.3 & 1.1 & 1.7 \\
\hline
\end{tabular}


As well as providing information about grain and phase distributions, TKD analysis also has the capability to analyse orientation relationships. The same region of oxide has been mapped by TKD before and after irradiation, with the corresponding pattern quality and phase maps shown in Figure 6 along with orientation maps for grains of both monoclinic and cubic phases. The alignment of low index poles of parent and product phases have been compared systematically in 3-dimensions to reveal their orientation relationships. Examples of contoured maps of the distribution of the $(100)_{c},[001]_{c}$ poles of $c-\mathrm{ZrO}_{2}$ and the $(100)_{\mathrm{m}},[001]_{\mathrm{m}}$ poles of $\mathrm{m}-\mathrm{ZrO}_{2}$ are plotted in Figure 6 (c) for the same region pre and post irradiation. Contoured pole figures from the whole region in the pre-irradiation specimen and the postirradiation specimen are shown in supplementary Figure S4. It can be seen that $(100)_{\mathrm{m}}$ and $[001]_{\mathrm{m}}$ are aligned with one of the corresponding poles or directions in the $\mathrm{c}-\mathrm{ZrO}_{2}$, indicating a $(100)_{m} \|(100)_{c}$ and $[001]_{m} \|[001]_{c}$ crystallographic relationship in agreement with the prediction of Cayron et al. [78].
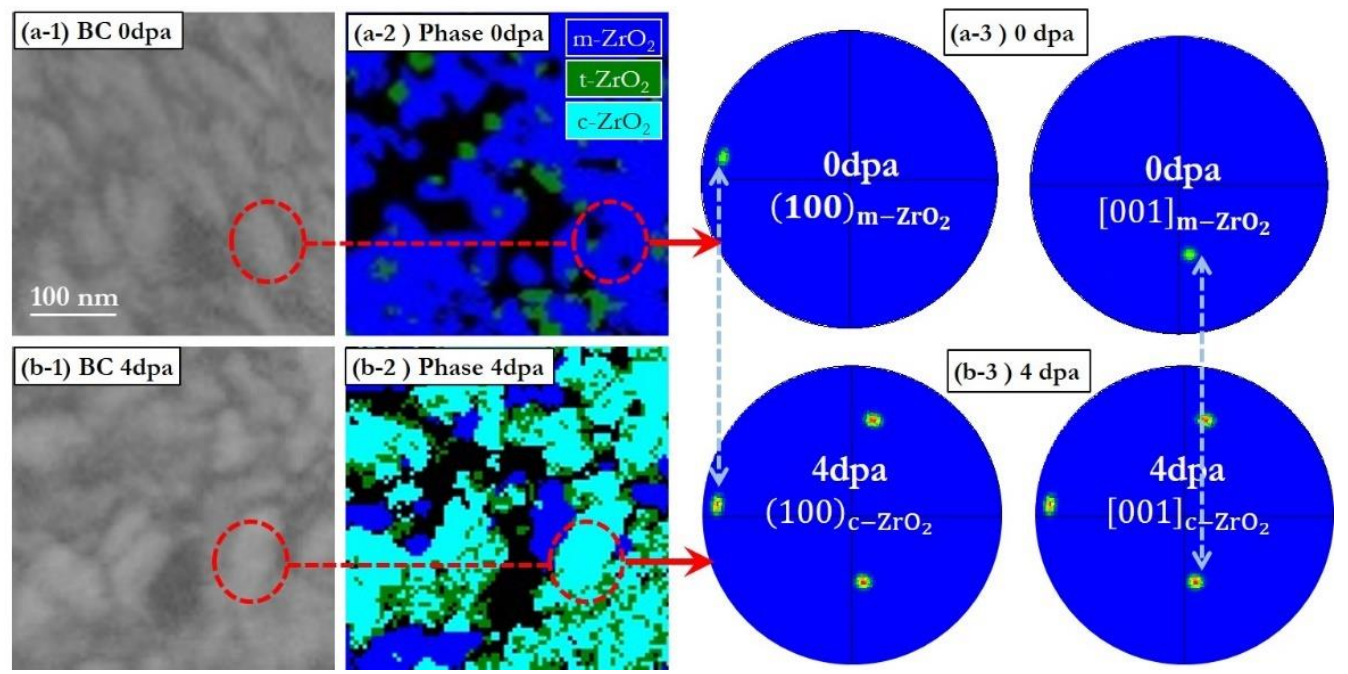

Figure 6 TKD pattern quality, phase maps and pole figures with stereographic projections (half width $5^{\circ}$ ) of the same region before and after in-situ irradiation: (a) $0 \mathrm{dpa}$, (b) $4 \mathrm{dpa}$ at $7.4 \times 10^{15}$ ions. $\mathrm{cm}^{-2}$.

\subsection{Evolution of irradiation-induced defects}

Figure 7 shows a set of Fresnel contrast TEM images taken during the in-situ irradiation experiment. A high density of small features with black/white contrast can be seen in the irradiated samples, Figure 7 ( $b$ and $c)$. The EDX and HAADF-STEM results shown in Figure 810 indicate these small features are mainly composed of vacancies, or clusters of vacancies, and for convenience these will simply be called voids below. Continuous growth of the voids 
is seen with increasing dose, and at $10 \mathrm{dpa}$ the average diameter is $\sim 1.5 \mathrm{~nm}$ as shown in Figure 7 (c).
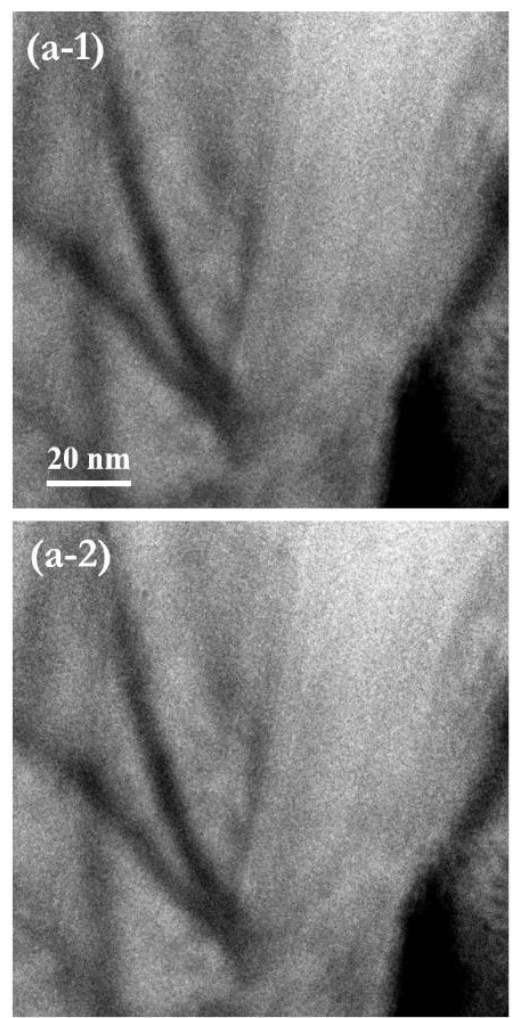
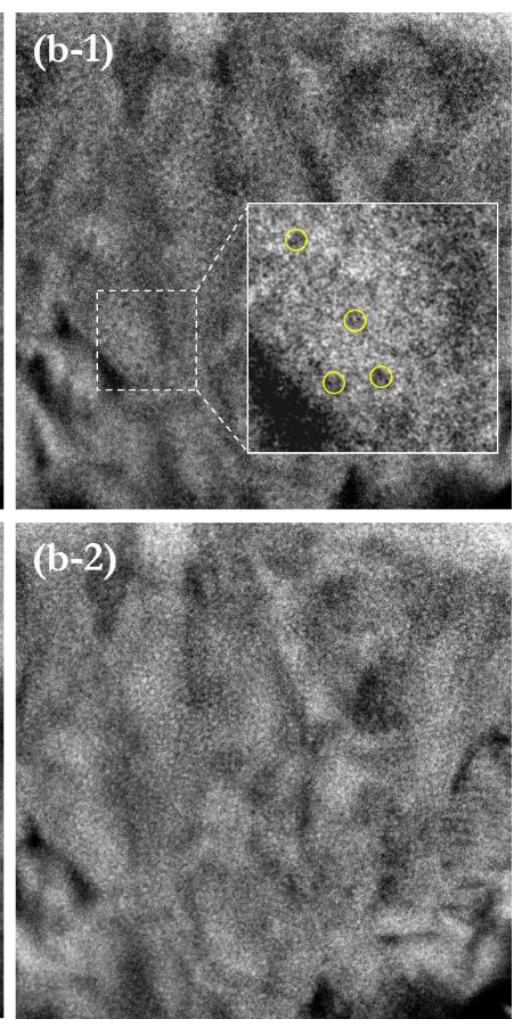
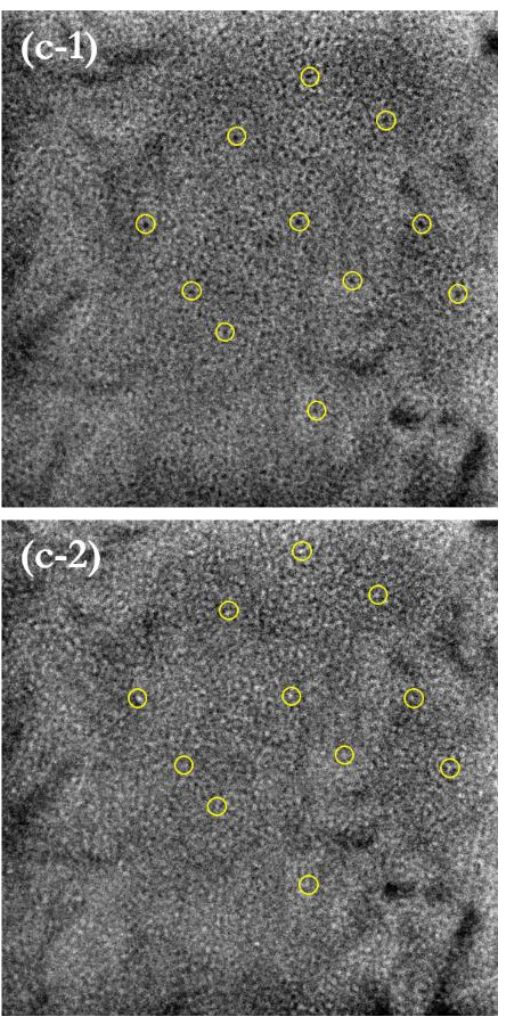

Figure 7 Fresnel contrast (top row $\Delta \mathrm{f}=500 \mathrm{~nm}$ over-focus, bottom row $\Delta \mathrm{f}=500 \mathrm{~nm}$ underfocus) bright-field TEM images of the same region showing the formation of voids at different in-situ irradiation doses; (a) $0 \mathrm{dpa}$, (b) $1 \mathrm{dpa}, 1.9 \times 10^{15} \mathrm{ions}_{\mathrm{cm}} \mathrm{cm}^{-2}$ and (c) $10 \mathrm{dpa}$, $1.9 \times 10^{16}$ ions. $\mathrm{cm}^{-2}$. Examples of voids are highlighted by yellow circles in images of the $1 \mathrm{dpa}$ and 10 dpa samples.

Under our in-situ irradiation conditions, a high density of vacancies can be formed at an early irradiation stage, e.g. after $1.9 \times 10^{15}$ ions.cm ${ }^{-2}(1 \mathrm{dpa})$, and these can condense to form small voids as shown in Figure 7 (b). This damage level is achievable in in-service nuclear cladding materials, and an example of similar small voids observed by the Fresnel imaging technique in the oxide on an in-reactor corroded Zr sample is shown in supplementary Figure S5 (b). These features were not observed in the autoclave-corroded samples after similar corrosion times, as can be seen in Figure S5 (a).

Extended ion tracks can be produced in ceramics irradiated by heavy ions with energies of hundreds to thousands of MeV, but only in materials with relatively high electronic stopping powers [79]. In our study, the electronic stopping power is estimated by SRIM to be only $\sim 0.3$ $\mathrm{keV} . \mathrm{nm}^{-1}$ and the incident ion energy is much lower so we believe that these irradiationinduced features are voids rather than ion tracks. The formation of inert gas bubbles in 
materials irradiated with $\mathrm{He}$ or $\mathrm{Kr}$ has been reported previously $[7,80]$ and will show essentially same contrast under Fresnel imaging conditions, but we believe that the voids seen in this study do not contain sufficient gas to be classed as bubbles. Based on Fell and Murphy's calculation [81], at least 50 gas atoms are required to nucleate bubbles $0.5 \mathrm{~nm}$ in diameter. As mentioned earlier, around $99 \%$ of the implanted $700 \mathrm{keV} \mathrm{Kr}{ }^{2+}$ ions should pass through TEM foils that are $15-50 \mathrm{~nm}$ in thickness, and after a dose of $1 \mathrm{dpa}\left(1.9 \times 10^{15}\right.$ ions.cm ${ }^{-}$ ${ }^{2}$ ) the residual concentration of $\mathrm{Kr}$ is estimated to be 0.005 at\%. Using these values, the ratio of the number of retained $\mathrm{Kr}$ ions to the number of observed voids can thus be estimated to be $<1$, far below that required to identify the features we observe as $\mathrm{Kr}$ bubbles. This is also confirmed by the EDX spectra in Figure 8 taken from two adjacent regions, one containing at least one void and the other avoiding all the obvious voids. The same analysis conditions (pixel size, dwell time and mapping area) are chosen so that these two spectra have similar background intensities. A small gallium peak is observed due to Ga implantation during FIB sample preparation, and the Cu peaks are the result of fluorescence from the $\mathrm{Cu}$-supporting grid. No detectable signal from $\mathrm{Kr}$ was observed, and the intensities of the $\mathrm{Zr}$ and $\mathrm{O}$ signals from the region covering the void features are $20 \%$ lower than those from the nearby matrix. With an average void diameter of $1.5 \mathrm{~nm}$ and a foil thickness of $15 \mathrm{~nm}$ these observations could be explained by the superposition of two voids through the foil thickness.

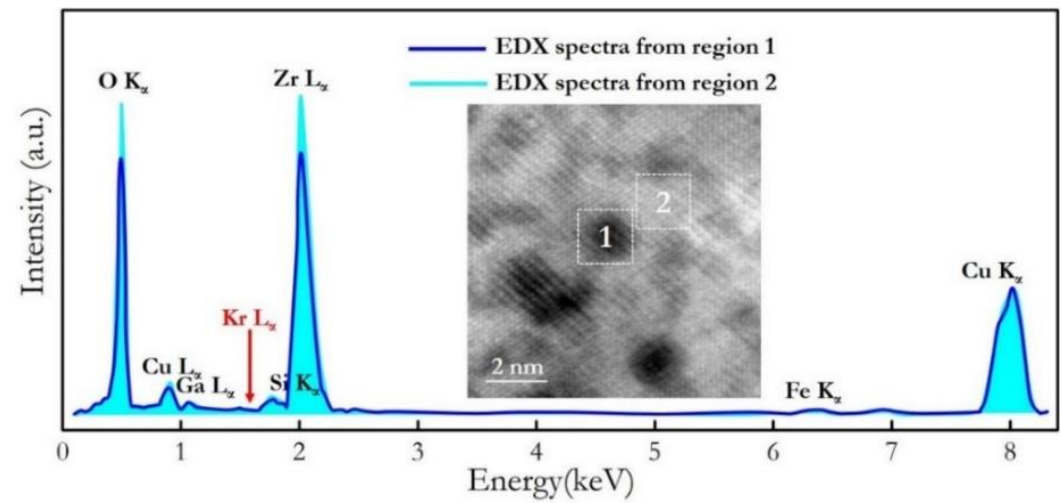

Figure 8 HAADF-STEM image showing irradiation-induced voids and EDX spectra from a void and an adjacent region of the matrix in the $10 \mathrm{dpa}$ specimen (voids are darker in the dark field mode because the surrounding area has a higher average atomic mass).

HAADF-STEM images showing the atomic structure around these voids are presented in

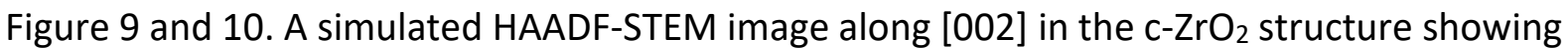
the positions of $\mathrm{Zr}, \mathrm{O}$ and interstitial sites is shown in Figure 9 (a). $\mathrm{Zr}$ atoms are brighter in this dark field mode because they have higher atomic mass than $\mathrm{O}$ atoms. This HAADF image was 
simulated with Dr. Probe software [82] with overexposure contrast to enhance the visibility of $\mathrm{O}$ atomic positions. The 3-dimensional model of the $\mathrm{c}-\mathrm{ZrO}_{2}$ crystal shown in Figure 9 (b) was built using CrystalMaker $^{\circledR}$ and the fluorite structure and space group Fm $\overline{3} m$, Wyckoff positions of $O$ atoms at $8 c$ sites at $(1 / 41 / 41 / 4)$ and $(1 / 41 / 43 / 4)$ adopting simple cubic packing, $\mathrm{Zr}$ at $4 \mathrm{a}$ sites at $(000)$, and interstitials at $4 \mathrm{~b}$ sites (in grey) or $24 \mathrm{~d}$ sites (in blue) [83]. A 2-dimensional image of this structure along [200] is superimposed on the simulated HAADF image in Figure 9 (a). The experimentally acquired HAADF-STEM image along [200] from a region of the 10 dpa specimen containing a void in Figure 9 (c) shows a very similar contrast to the simulated image, but the atomic columns at the location of the void show darker contrast compared to the surrounding matrix. In this kind of image, the intensity in each atomic column scales with the average atomic number $Z$, and darker contrast thus identifies columns containing a high concentration of vacant sites as expected if a void is buried in the sample thickness. An intensity profile along the [011] direction crossing the void region is plotted in Figure 9 (d). The high-intensity peaks correspond to $\mathrm{Zr}$ atomic columns at $4 \mathrm{a}$ Wyckoff positions, and the lowest-intensity regions correspond to the overlapping locations of $\mathrm{O}$ atomic columns at $8 \mathrm{c}$ Wyckoff positions and interstitial sites at $24 \mathrm{~d}$ Wyckoff positions (when imaged along [200], the $O$ atoms at $8 c$ sites and 24d Wyckoff positions are superimposed). Some columns in these low-intensity regions show significantly brighter contrast than expected, as shown in Figure 9 (d), suggesting that these contain extra atoms on interstitial positions. Considering the Z-contrast dominated nature of HAADF images [66], these are likely to be Zr interstitials. In addition, some of Zr columns away from the void region show brighter contrast in the HAADF-STEM images in both Figure 9 (c) and 10 (a). A line profile showing intensities of these brighter $\mathrm{Zr}$ columns is presented in supplementary Figure S3(c), and this excess contrast may originate from interstitial defects occupying the $4 \mathrm{~b}$ sites. 
(a) Simulated HAADF

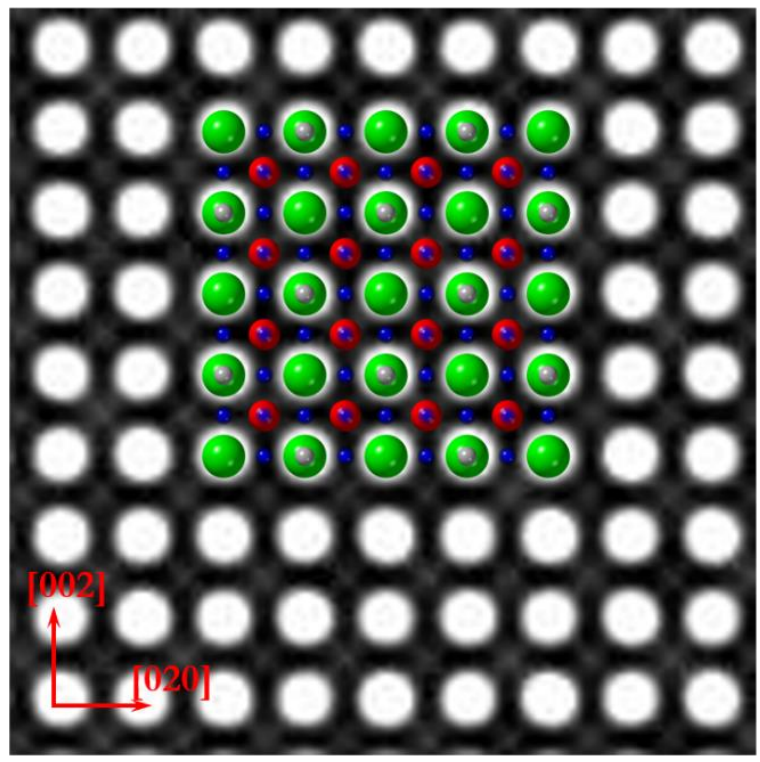

(c) Experimental HAADF

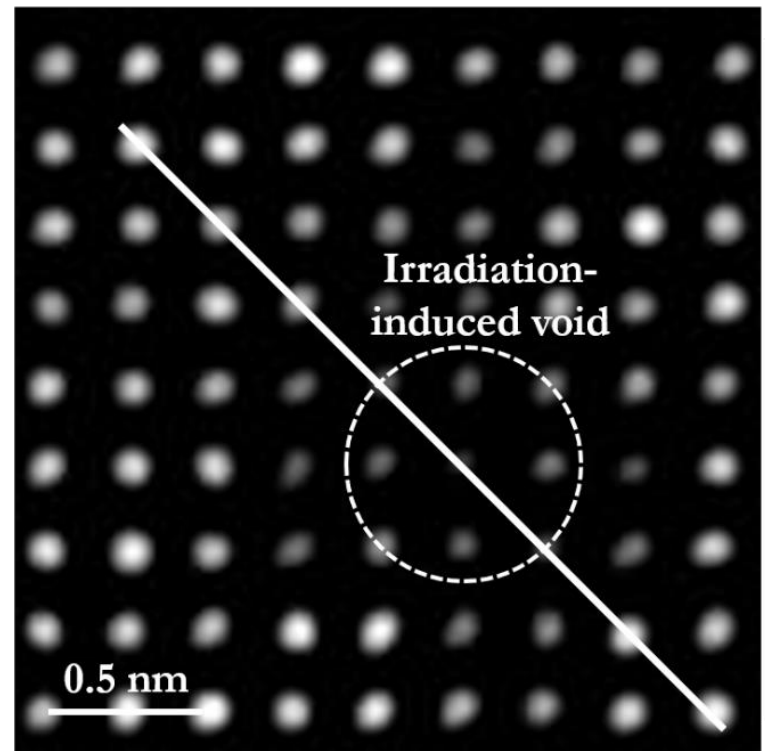

(b) Crystal structure of cubic- $\mathrm{ZrO}_{2}$

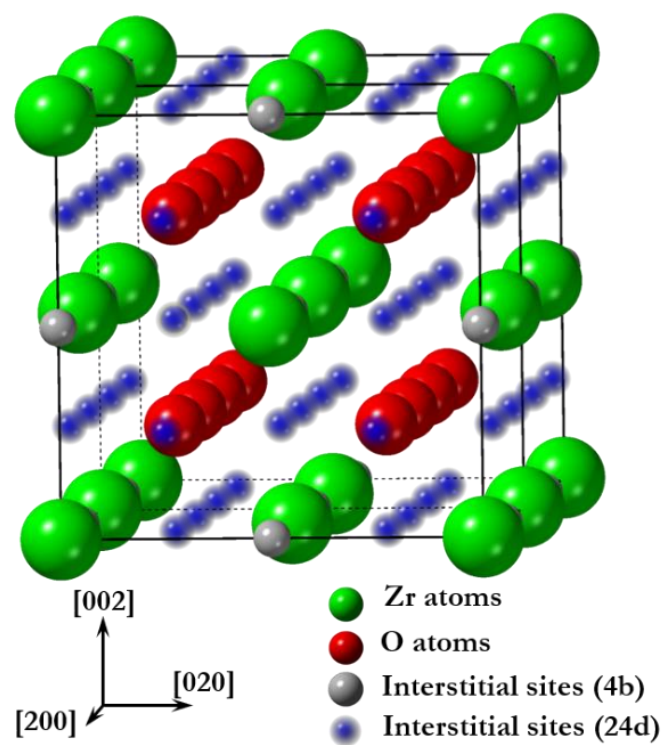

(d) Line profile

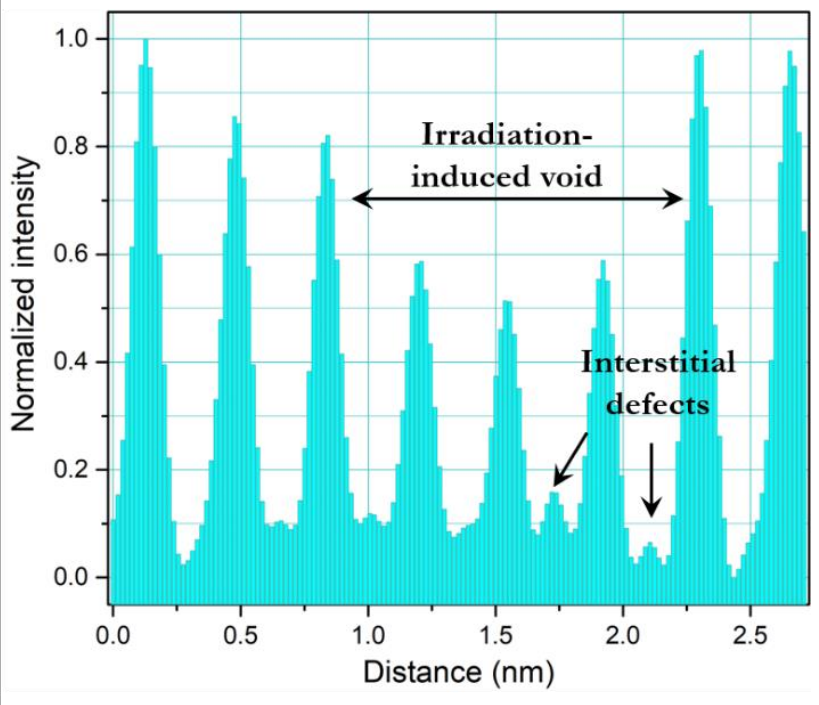

Figure 9 (a) Simulated HAADF image oriented along [200] with overexposure contrast showing the atomic positions. $\mathrm{Zr}$ atoms are brighter in the dark field mode because they have a higher atomic mass than $\mathrm{O}$ atoms. The crystal model showing $\mathrm{Zr}$ (green), $\mathrm{O}$ (red) and interstitial (grey: 4b, blue:24d) sites is superimposed on the image. (b) Crystal model of c$\mathrm{ZrO}_{2}$ showing atomic and interstitial positions. (c) Experimental HAADF image oriented along [200] acquired from the 10 dpa specimen. An irradiation-induced void is highlighted by the white dashed circle. Voids are darker because the surrounding area has a higher average atomic mass. (d) Intensity line profile along [011] from the line highlighted in (c). 
(a) HAADF

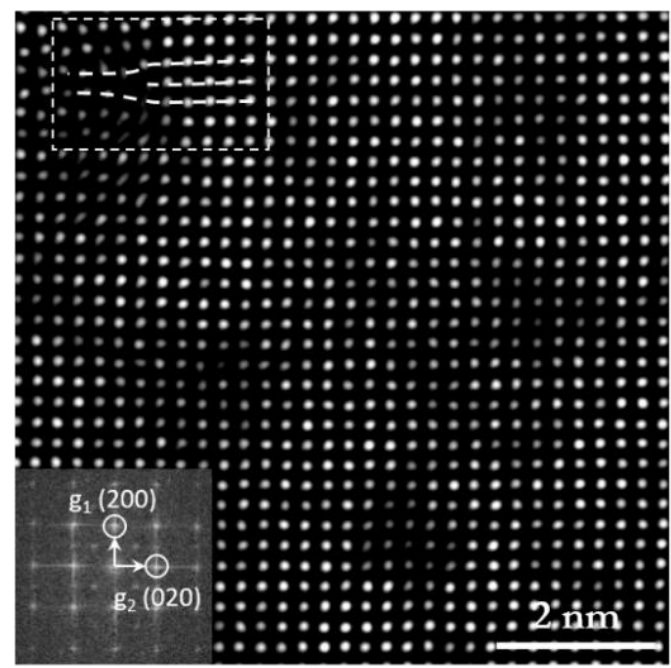

(c) GPA strain map, $\varepsilon_{\mathrm{yy}}(\mathrm{g}=200)$

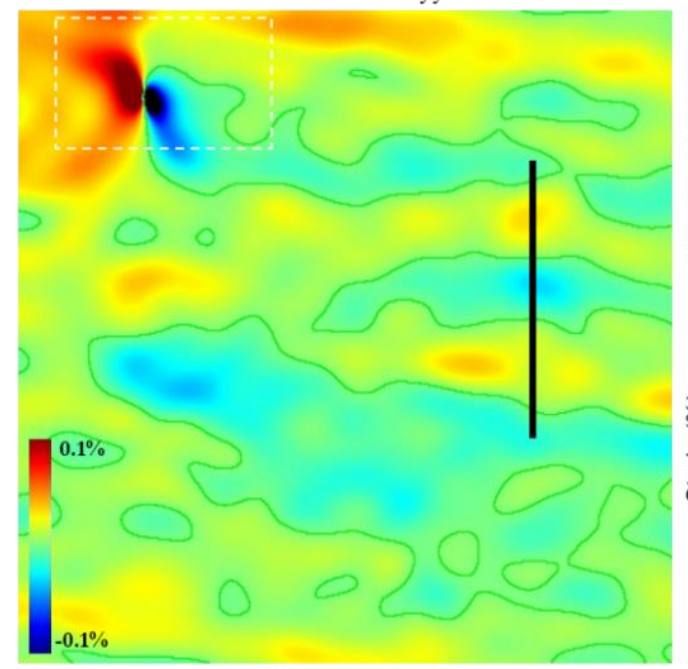

(b) Filtered HAADF

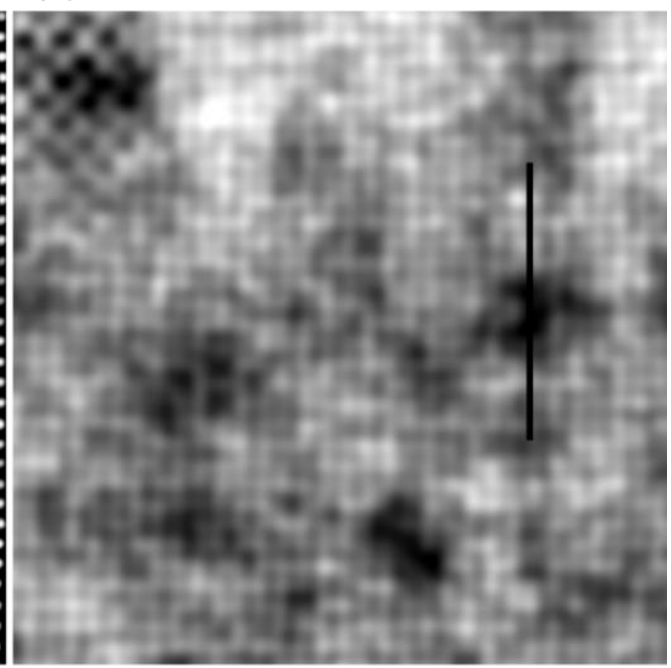

(d) Line profiles

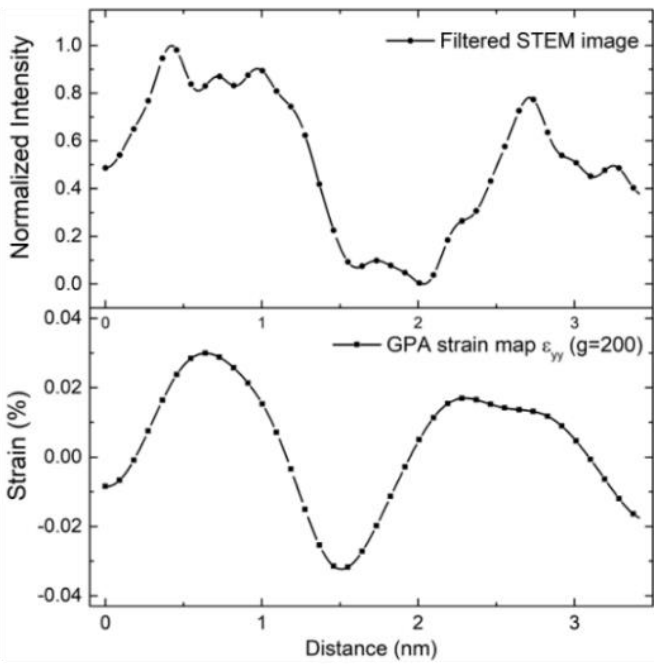

Figure 10 (a) Experimental HAADF image acquired along [002] from the $10 \mathrm{dpa}$ specimen. The Fourier vectors selected for geometric phase analysis are shown as $g_{1}$ and $g_{2}$. (b) Low-

Pass Fourier transformation filtered HAADF image showing the locations of irradiationinduced voids. (c) Strain components $\varepsilon_{y y}$ derived by GPA, the green contour lines indicate the locations where the calculated strain level is 0 . (d) Line profiles showing the local strain around an irradiation-induced void along the paths marked in (b) and (c). The white dashed rectangles in (a) and (c) highlight a region containing an edge dislocation.

Strain distributions around these voids were also investigated using the GPA method [68]. The HAADF-STEM image from the $10 \mathrm{dpa}$ specimen used for GPA analysis is shown in Figure 10 (a) with its Fast Fourier Transformation (FFT). By applying a low-pass filter, the locations and morphologies of several voids are highlighted in Figure 10 (b). The (002) and (020) spots were chosen for geometric phase analysis, and masks of size $1.9 \mathrm{~nm}^{-1}$ in Fourier space were placed around these spots to isolate them as shown in Figure 10 (a). The GPA generates strain maps 
with colour contours that directly illustrate the locations of regions with relative strains. Defining the $x$-axis parallel to [020] and the y-axis parallel to [002], the calculated strain field along the y-direction is shown in Figure 10 (c). The colour scale indicates strain changes ranging from $-0.1 \%$ to $+0.1 \%$, with the blue regions having negative strains closely matching the regions with dark contrast in the filtered HAADF image in Figure 10 (b), revealing the local compressive strains induced by the voids. An edge dislocation can be seen in the upper left corner in the HAADF image in Figure 10 (a), and the local compression/tension regions can also be seen at the same location in Figure 10 (c), as expected. The magnitude of the strain levels for a single edge dislocation calculated using the GPA method in this study is close to that calculated by the high-angular resolution TKD (HR-TKD) method in pure tungsten [75]. The line profiles in Figure 10 (d) from the marked locations in (b) and (c) again show the colocation of an irradiation-induced void and a region with significant compressive strain.

\section{Discussion}

\subsection{Irradiation-induced phase transformation and grain growth}

The results presented above show that nano-crystalline $\mathrm{m}-\mathrm{ZrO}_{2}$ grains in a thin TEM are transformed into the higher symmetry cubic phase under in-situ ion irradiation, without any evidence for the formation of an intermediate tetragonal phase. The mechanisms of phase transformations between the different phases of zirconia upon deformation or thermal treatment have been widely studied [84-87], but this kind of direct transformation from the monoclinic to cubic structures has only been observed under irradiation [25-28] and is supposed to occur in a displacive manner $[29,46,88]$. To explore the nature of this transformation it is necessary to analyze the orientation relationship between the two phases, which was predicted to be $(100)_{m} \|(100)_{c}$ and $[001]_{m} \|[001]_{c}[78]$ and confirmed in this work. In Figure S6 in the supplementary information, we show the reconstructed atomic arrangements of the (100) planes in the monoclinic and cubic phases, respectively, and a high degree of coherency can be achieved at a $(100)_{\mathrm{m}} \|(100)_{\mathrm{c}}$ interface. Transformation from the monoclinic to cubic phase induces a strain of approximately $-4.7 \%$ along $[001]_{\mathrm{m}}$, which is parallel with $[001]_{c}$, and $-2.7 \%$ along the $[010]_{m}$ direction. Since an angular misfit exists between $[001]_{m}$ and $[100]_{c}\left(\beta_{m}=99.25^{\circ}\right.$ and $\left.\beta_{c}=90^{\circ}\right)$ a larger strain might be expected along $[100]_{\mathrm{m}}$. In other words, $\mathrm{c}-\mathrm{ZrO}_{2}$ can be obtained from the monoclinic phase by a uniform shear 
transformation along $[001]_{\mathrm{m}}$ plus small contractions along the three principal axes. The transformed high-temperature $\mathrm{c}-\mathrm{ZrO}_{2}$ phase can then be stabilized by strain fields induced by a high density of irradiation-induced defect clusters [46] as discussed below.

\subsection{Structure of irradiation-induced defect clusters}

In this work, we have focussed on the atomic structure and formation mechanisms of irradiation-induced defects. Our experimental results show a high density of void-like features that we identify as vacancy clusters in agreement with previous modelling studies $[9,10]$. As discussed in section 1.1, $\mathrm{O}$ defects (vacancies $\mathrm{V}_{\mathrm{O}}^{*}$ and interstitials $\mathrm{O}_{\mathrm{i}}$ ) have much lower migration activation energies than $\mathrm{Zr}$ defects [9], so a substantial fraction of the mobile $\mathrm{O}$ vacancies created during the displacement spike will migrate to immobile $\mathrm{Zr}$ vacancies to form Schottky defects centred on the $\mathrm{Zr}$ lattice positions. These defects can then condense to form the voids detected as $\mathrm{Zr}$ atomic columns with darker contrast in the Z-contrast HAADF-STEM images in Figure 9 and 10. Increasing the irradiation dose will create more Schottky defects, and lead to the continuous growth of the voids shown in Figure 7.

Our analysis of the irradiated samples using aberration-corrected HAADF-STEM at atomic resolution suggests the formation of interstitial defects, Figure 9, in agreement with previous work on heavy ion irradiated nano-structured zirconia $[11,12]$. Due to high activation energy for migration of these interstitials [9], especially $Z r_{i}^{\cdots}{ }^{\cdots}$, they are rather immobile and, if created far enough from sinks, most interstitials will exist as isolated defects like those we have observed, or in small clusters (previous modelling studies indicate the largest stable interstitial cluster in zirconia is consistently between three and four interstitials regardless of Primary Knock-on Atom (PKA) energies [16]). In most modelling studies on the incorporation of interstitials into fluorite-structured oxides $\left(\mathrm{ZrO}_{2}, \mathrm{CeO}_{2}\right.$ and $\left.\mathrm{UO}_{2}\right)$, only the $4 \mathrm{~b}$ Wyckoff positions (Fm $\overline{3} m$ structure) are taken into account $[10,89,90]$. However, our experimental results indicate the $24 \mathrm{~d}$ Wyckoff positions or vacant oxygen sites at $8 \mathrm{c}$ sites may also be favourable for interstitial occupation. A recent modelling study on cubic zirconia shows that the $24 \mathrm{~d}$ and $4 \mathrm{~b}$ sites have similar incorporation energies for iodine interstitials [83].

In agreement with previous work [89, 91, 92], we find that the observed defect clusters significantly distort the nearby lattice, Figure 10 . The measured local lattice strain is $\sim-0.03 \%$ around the voids in the zirconia specimen irradiated to $10 \mathrm{dpa}$. The number density and size 
of these voids increase with irradiation dose, leading to a buildup of lattice strain that can stabilise the high temperature cubic phase [46].

\subsection{Relevance of this study for in-service performance of Zr alloys}

Under typical in-reactor conditions the neutron-induced damage rate is of the order of $10^{-7}$ dpa.s ${ }^{-1}$ [93], 4 orders of magnitude lower than that induced by ion irradiation in the current study. As a result, the formation of the monoclinic and a small fraction of tetragonal phase is normally reported in the outer surface oxides of the cladding $[69,70]$ rather than the cubic phase reported here. In service, however, both the outer and inner cladding surfaces are progressively oxidised by oxygen containing species from the coolant water or fuel pellets [3, 28]. The oxide layers in both locations can degrade the thermal and mechanical properties of fuel rods and limit their lifetime, so it is important to understand their evolution under irradiation in order to improve the modelling of rod behaviour in the reactor. In order to increase the resistance of the cladding to pellet cladding interactions, a pure $\mathrm{Zr}$ liner (or a layered structure with pure $\mathrm{Zr}$ as one of the layers, e.g. TRICLAD) is often coated on the inner cladding surface [94], and we note that the formation of cubic zirconia has been observed on this inner cladding surface [28] of Zr alloys in high burnup boiling water reactor (BWR) fuels.

As mentioned in the introduction, the oxides formed on the inner surface of the cladding are exposed to a high flux of energetic ions from decay processes as well as irradiation with neutrons [5]. Nogita et. al. [28] used XRD to examine the oxides formed on the $\mathrm{Zr}$ liner cladding surface irradiated to burnups of 15,27 and $42 \mathrm{GWd} . \mathrm{t}^{-1}$ and found the oxides were initially monoclinic, but after high burnups, all of them had transformed into the cubic structure. More recently, Lach et. al. [95] used precession electron diffraction (PED) - a TEMbased technique similar to TKD - to analyse the Zr liner cladding surface irradiated to a burnup of $70 \mathrm{GWd} \cdot \mathrm{t}^{-1}$ and found the oxide layer contained multiple phases that depend on oxide depth, with what were identified as large tetragonal $\mathrm{ZrO}_{2}$ grains in the outer 5-6 $\mu \mathrm{m}$, a mixture of tetragonal and monoclinic in the middle and small monoclinic grains close to the zirconium metal matrix. However PED has a relatively low angular resolution compared with TKD [74, 75] and it is thus challenging to distinguish grains of cubic and tetragonal $\mathrm{ZrO}_{2}$. The ongoing corrosion process means that the levels of irradiation damage accumulated in the oxide layer depends on when the oxide was formed, and means that the earlier the oxides are formed the more damage they will have accumulate. It is also reported that $\sim 98 \%$ of the fission 
products (e.g. ${ }^{60} \mathrm{Co},{ }^{85} \mathrm{Kr}$ and ${ }^{106} \mathrm{Ru}$ ) have a penetration depth less than $10 \mu \mathrm{m}$ into the fuel cladding [5], so that the most intense irradiation damage will occur in the outer oxide on the inner surface of the cladding. As a result, irradiation-induced phase transformations and grain growth processes are most likely to be stimulated in this location, as observed in [95]. Our results demonstrate that the stabilisation of $\mathrm{c}-\mathrm{ZrO}_{2}$ can be achieved solely by the accumulation of irradiation-induced defects under in-situ heavy ion irradiation, and hence we propose that a mechanism based on defects induced by the high flux of fission fragments and neutrons can explain the stabilisation of the cubic oxide phase at the inner surface of the cladding under in-reactor conditions without the need to invoke any chemical doping effect by implanted fission products [96].

Radiation damage in the outer surface oxides of the cladding is mainly induced by neutrons and thus the accumulated damage in the oxides on the outer cladding surface is lower than the inner surface. However, we have also shown a high density of irradiation-induced voids can be formed in this oxide on a long-term in-reactor corroded Zr samples, Figure S5, so the possibility of radiation-induced stabilisation of the cubic oxide phase thus needs to be considered when developing future cladding alloys for very high burnups. The stabilization of metastable oxide phases has been reported to be important in controlling the corrosion performance of $\mathrm{Zr}$ alloys [4, 31, 43]. If the stabilisation conditions fail, the tetragonal to monoclinic (or cubic to monoclinic) transformation will take place, and nano-scale cracks and porosity can be created as a consequence of the $\sim 6 \%$ volume change creating fast ingress routes for oxygen containing species, thus reducing the protective nature of the oxide film and accelerating the rate of hydrothermal degradation [31, 97].

\section{Conclusions}

The present study has made extensive use of advanced in-situ damage and microstructural analysis techniques to study irradiation damage in zirconium oxides formed by the corrosion of zirconium fuel cladding alloys with an unprecedented level of detail. High-resolution TKD orientation mapping was used in combination with in-situ irradiation in the TEM for the first time. TKD can clearly show the evolution of grain size, texture and phase content in irradiated nanocrystalline materials, which is challenging for TEM techniques. By using HAADF-STEM analysis the atomic configurations of irradiation-induced defect clusters in zirconia have also 
been resolved. This combination of analytical microscopies has been shown to be a powerful method to probe the fundamental mechanisms controlling irradiation-induced changes in nanostructured materials. The following conclusions can be drawn from the results presented above;

1. Irradiation-induced formation of voids, phase transformations and grain growth have all been observed in $\mathrm{m}-\mathrm{ZrO}_{2}$ oxide scales on a model nuclear zirconium alloy. The product of the irradiation-induced phase transformation under in-situ heavy ionirradiation conditions is the high-temperature cubic phase rather than the tetragonal phase that has been previously reported. The transformation is martensitic in nature and, from consideration of the observed $(100)_{\mathrm{m}} \|(100)_{\mathrm{c}}$ and $[001]_{\mathrm{m}} \|[001]_{\mathrm{c}}$ orientation relationship between the parent and product phases, could occur by uniform shear along one of the principal axes of the $\mathrm{m}-\mathrm{ZrO}_{2}$ structure and contraction along the three principal axes. We also suggest that the stabilization of the cubic structure can be explained by the build-up of strain caused by irradiation-induced voids.

2. In-reactor materials are exposed to a high flux of energetic ions as well as the more often studied neutron damage. This study shows that heavy ion irradiation with $\mathrm{Kr}$ ions is a useful proxy to study the radiation damage from fission products. These results provide insights into the mechanism controlling irradiation-induced phase transformations and grain growth phenomenon particularly in the oxides formed on the inner surface of nuclear $\mathrm{Zr}$ cladding alloys in-service. The stabilisation of metastable $\mathrm{c}-\mathrm{ZrO}_{2}$ in this region can be explained wholly by the accumulation of irradiation damage induced by energetic fission fragments.

3. Oxides on the outer Zr cladding surface are exposed to much lower irradiation damage rates compared with the inner surface, so irradiation-induced phase transformation and grain growth may not be obvious at low burnups (or damage dose). However, when designing new fuel cladding materials to achieve very high burnups, we must consider the possibility of both irradiation-induced stabilisation of metastable phases and the formation of voids as processes that can occur in the oxides that will form on both surfaces. Understanding these changes in oxide microstructure is important as they may lead to enhanced corrosion rates, and serve as one possible degradation mechanism limiting the achievable fuel burnup. 


\section{Acknowledgements}

The authors acknowledge the contribution made to this work by their collaborators from Westinghouse and the MUZIC project providing zirconium samples. Support for work on active samples was provided by EPSRC grant (EP/M018237/1). Some of the work on radioactive samples was done using UKAEA's Materials Research Facility (MRF), which has been funded by the UK's National Nuclear User Facility (NNUF) and Henry Royce Institute initiative. Access to the MIAMI-2 facilities was provided through the EPSRC UK National Ion Beam Centre (NS/A000059/1, http://www.uknibc.co.uk/). EPSRC grants (EP/K040375/1 and EP/N010868/1) are acknowledged for funding the 'South of England Analytical Electron Microscope' and the Zeiss Crossbeam FIB/SEM used in this research. JL is grateful for the support from EPSRC grant (EP/P001645/1). AHM, JH and SD would acknowledge the funding grants EP/E017266/1, EP/T012811/1, EP/M011135/1 and EP/M028283/1 from EPSRC. We thank Diamond Light Source for access and support in use of the electron Physical Science Imaging Centre (Instrument E02 and proposal numbers EM20528 and MG23235) that contributed to the results presented here. 


\section{Reference}

[1] W.L. Gong, W. Lutze, R.C. Ewing, Zirconia ceramics for excess weapons plutonium waste, Journal of Nuclear Materials 277(2) (2000) 239-249.

[2] H. Akie, H. Takano, T. Muromura, N. Nitani, A new idea of excess plutonium oncethrough burning in light water reactor, Progress in Nuclear Energy 29 (1995) 345-352.

[3] A.T. Motta, A. Couet, R.J. Comstock, Corrosion of zirconium alloys used for nuclear fuel cladding, Annual Review of Materials Research 45 (2015) 311-343.

[4] M. Preuss, P. Frankel, S. Lozano-Perez, D. Hudson, E. Polatidis, N. Ni, J. Wei, C. English, C. English, C. English, S. Storer, K.B. Chong, M. Fitzpatrick, P. Wang, J. Smith, C. Grovenor, G. Smith, J. Sykes, B. Cottis, S. Lyon, L. Hallstadius, R.J. Comstock, A. Ambard, M. Blat-Yrieix, Studies regarding corrosion mechanisms in zirconium alloys, in: M. Limbäck, P. Barbéris (Eds.), ASTM International, West Conshohocken, PA, 2012, pp. 649-681.

[5] T. Hirabayashi, T. Sato, C. Sagawa, N.M. Masaki, M. Saeki, T. Adachi, Distributions of radionuclides on and in spent nuclear fuel claddings of pressurized water reactors, Journal of Nuclear Materials 174(1) (1990) 45-52.

[6] D.S. Aidhy, P.C. Millett, T. Desai, D. Wolf, S.R. Phillpot, Kinetically evolving irradiationinduced point defect clusters in $\mathrm{UO}_{2}$ by molecular dynamics simulation, Physical Review $\mathrm{B}$ 80(10) (2009) 104107.

[7] I.J. Beyerlein, A. Caro, M.J. Demkowicz, N.A. Mara, A. Misra, B.P. Uberuaga, Radiation damage tolerant nanomaterials, Materials Today 16(11) (2013) 443-449.

[8] K. Govers, S. Lemehov, M. Hou, M. Verwerft, Comparison of interatomic potentials for $\mathrm{UO}_{2}$. Part I: Static calculations, Journal of Nuclear Materials 366(1) (2007) 161-177.

[9] D.S. Aidhy, Y. Zhang, W.J. Weber, Radiation damage in cubic ZrO2 and yttria-stabilized zirconia from molecular dynamics simulations, Scripta Materialia 98 (2015) 16-19.

[10] Y. Dong, L. Qi, J. Li, I.W. Chen, A computational study of yttria-stabilized zirconia: II. Cation diffusion, Acta Materialia 126 (2017) 438-450.

[11] S. Dey, J. Mardinly, Y. Wang, J.A. Valdez, T.G. Holesinger, B.P. Uberuaga, J.J. Ditto, J.W. Drazin, R.H. Castro, Irradiation-induced grain growth and defect evolution in nanocrystalline zirconia with doped grain boundaries, Physical Chemistry Chemical Physics 18(25) (2016) 16921-16929.

[12] S. Dey, J.W. Drazin, Y. Wang, J.A. Valdez, T.G. Holesinger, B.P. Uberuaga, R.H.R. Castro, Radiation tolerance of nanocrystalline ceramics: insights from yttria stabilized zirconia, Scientific Reports 5 (2015) 7746.

[13] H.Y. Xiao, Y. Zhang, W.J. Weber, Ab initio molecular dynamics simulations of low-energy recoil events in $\mathrm{ThO}_{2}, \mathrm{CeO}_{2}$, and $\mathrm{ZrO}_{2}$, Physical Review B 86(5) (2012) 054109.

[14] B. Liu, H. Xiao, Y. Zhang, D.S. Aidhy, W.J. Weber, Investigation of oxygen point defects in cubic ZrO2 by density functional theory, Computational Materials Science 92 (2014) 22-27.

[15] J. Heikinheimo, S. Ortner, I. Makkonen, J. Kujala, M. Blackmur, F. Tuomisto, Positron annihilation analysis of the atomic scale changes in oxidized Zircaloy-4 samples, Journal of Nuclear Materials 495 (2017) 172-180.

[16] E. Zarkadoula, R. Devanathan, W.J. Weber, M.A. Seaton, I.T. Todorov, K. Nordlund, M.T. Dove, K. Trachenko, High-energy radiation damage in zirconia: Modeling results, Journal of Applied Physics 115(8) (2014) 083507.

[17] L.C. Damonte, M.A. Taylor, J. Desimoni, J. Runco, PALS study on the defect structure of yttria-stabilized zirconia, Radiation Physics and Chemistry 76(2) (2007) 248-251. 
[18] B.P. Uberuaga, L.J. Vernon, E. Martinez, A.F. Voter, The relationship between grain boundary structure, defect mobility, and grain boundary sink efficiency, Scientific Reports 5 (2015) 9095.

[19] A.G. Balogh, Irradiation induced defect formation and phase transition in nanostructured $\mathrm{ZrO}_{2}$, Nuclear Instruments and Methods in Physics Research Section B: Beam Interactions with Materials and Atoms 282 (2012) 48-58.

[20] Y. Zhang, W. Jiang, C. Wang, F. Namavar, P.D. Edmondson, Z. Zhu, F. Gao, J. Lian, W.J. Weber, Grain growth and phase stability of nanocrystalline cubic zirconia under ion irradiation, Physical Review B 82(18) (2010) 184105.

[21] B. Schuster, M. Lang, R. Klein, C. Trautmann, R. Neumann, A. Benyagoub, Structural phase transition in $\mathrm{ZrO} 2$ induced by swift heavy ion irradiation at high-pressure, Nuclear Instruments and Methods in Physics Research Section B: Beam Interactions with Materials and Atoms 267(6) (2009) 964-968.

[22] D. Simeone, D. Gosset, J.L. Bechade, A. Chevarier, Analysis of the monoclinic-tetragonal phase transition of zirconia under irradiation, Journal of Nuclear Materials 300(1) (2002) 2738.

[23] P. Balasaritha, S. Amirthapandian, P. Magudapathy, R.M. Sarguna, S.K. Srivastava, B.K. Panigrahi, lon beam induced phase transformation and krypton bubble formation in monoclinic zirconium oxide, Journal of Nuclear Materials 508 (2018) 385-394.

[24] A. Benyagoub, Phase stability of the two isomorphs monoclinic zirconia and hafnia under MeV ion irradiation, Acta Materialia 60(16) (2012) 5662-5669.

[25] M.C. Wittels, F.A. Sherrill, Irradiation-induced phase transformation in zirconia, Journal of Applied Physics 27(6) (1956) 643-644.

[26] J. Adam, B. Cox, Neutron and fission fragment damage in zirconia, Physical Review Letters 3(12) (1959) 543-544.

[27] E.R. Vance, J.N. Boland, Fission fragment irradiation of single crystal monoclinic $\mathrm{ZrO}_{2}$, Radiation Effects 37(3-4) (1978) 237-239.

[28] K. Nogita, K. Une, Formation of pellet-cladding bonding layer in high burnup BWR fuels, Journal of Nuclear Science and Technology 34(7) (1997) 679-686.

[29] K.E. Sickafus, H. Matzke, T. Hartmann, K. Yasuda, J.A. Valdez, P. Chodak lii, M. Nastasi, R.A. Verrall, Radiation damage effects in zirconia, Journal of Nuclear Materials 274(1) (1999) 66-77.

[30] Y. Dong, L. Qi, J. Li, I.W. Chen, A computational study of yttria-stabilized zirconia: I. Using crystal chemistry to search for the ground state on a glassy energy landscape, Acta Materialia 127 (2017) 73-84.

[31] J. Hu, J. Liu, S. Lozano-Perez, C.R.M. Grovenor, M. Christensen, W. Wolf, E. Wimmer, E.V. Mader, Hydrogen pickup during oxidation in aqueous environments: The role of nanopores and nano-pipes in zirconium oxide films, Acta Materialia 180 (2019) 105-115.

[32] S. Fabris, A.T. Paxton, M.W. Finnis, A stabilization mechanism of zirconia based on oxygen vacancies only, Acta Materialia 50(20) (2002) 5171-5178.

[33] M. Raza, D. Cornil, J. Cornil, S. Lucas, R. Snyders, S. Konstantinidis, Oxygen vacancy stabilized zirconia (OVSZ); a joint experimental and theoretical study, Scripta Materialia 124 (2016) 26-29.

[34] E. Polatidis, P. Frankel, J. Wei, M. Klaus, R.J. Comstock, A. Ambard, S. Lyon, R.A. Cottis, M. Preuss, Residual stresses and tetragonal phase fraction characterisation of corrosion tested Zircaloy-4 using energy dispersive synchrotron X-ray diffraction, Journal of Nuclear Materials 432(1) (2013) 102-112. 
[35] W. Qin, C. Nam, H.L. Li, J.A. Szpunar, Tetragonal phase stability in $\mathrm{ZrO}_{2}$ film formed on zirconium alloys and its effects on corrosion resistance, Acta Materialia 55(5) (2007) 16951701.

[36] D. J. Kim, Effect of $\mathrm{Ta}_{2} \mathrm{O}_{5}, \mathrm{Nb}_{2} \mathrm{O}_{5}$, and $\mathrm{HfO}_{2}$ alloying on the transformability of $\mathrm{Y}_{2} \mathrm{O}_{3}-$ stabilized tetragonal $\mathrm{ZrO}_{2}$, Journal of the American Ceramic Society 73(1) (1990) 115-120.

[37] P. Li, I.-W. Chen, J.E. Penner-Hahn, Effect of dopants on zirconia stabilization-an X-ray absorption study: III, Charge-Compensating Dopants, Journal of the American Ceramic Society 77(5) (1994) 1289-1295.

[38] A.S. Foster, V. Sulimov, F.L. Gejo, A. Shluger, R.M. Nieminen, Structure and electrical levels of point defects in monoclinic zirconia, Physical Review B 64(22) (2001) 224108. [39] S. Fabris, A.T. Paxton, M.W. Finnis, Relative energetics and structural properties of zirconia using a self-consistent tight-binding model, Physical Review B 61(10) (2000) 66176630.

[40] P. Villella, S. Conradson, F. Espinosa-Faller, S. Foltyn, K. Sickafus, J. Valdez, C. Degueldre, Local atomic structure in cubic stabilized zirconia, Physical Review B 64(10) (2001) 104101. [41] R. Devanathan, W.J. Weber, Dynamic annealing of defects in irradiated zirconia-based ceramics, Journal of Materials Research 23(3) (2011) 593-597.

[42] X. Lu, K. Liang, S. Gu, Y. Zheng, H. Fang, Effect of oxygen vacancies on transformation of zirconia at low temperatures, Journal of Materials Science 32(24) (1997) 6653-6656.

[43] J. Liao, Z. Yang, S. Qiu, Q. Peng, Z. Li, J. Zhang, The correlation between tetragonal phase and the undulated metal/oxide interface in the oxide films of zirconium alloys, Journal of Nuclear Materials 524 (2019) 101-110.

[44] S. Moll, L. Thomé, G. Sattonnay, A. Debelle, F. Garrido, L. Vincent, J. Jagielski, Multistep damage evolution process in cubic zirconia irradiated with MeV ions, Journal of Applied Physics 106(7) (2009) 073509.

[45] G. Sattonnay, M. Lahrichi, M. Herbst-Ghysel, F. Garrido, L. Thomé, Stress field induced by swift heavy ion irradiation in cubic yttria stabilized zirconia, 101(10) (2007) 103516.

[46] D. Simeone, G. Baldinozzi, D. Gosset, S. LeCaër, L. Mazerolles, Impact of radiation defects on the structural stability of pure zirconia, Physical Review B 70(13) (2004) 134116. [47] M. Kilo, M. Taylor, C. Argirusis, G. Borchardt, B. Lesage, S. Weber, S. Scherrer, H. Scherrer, M. Schroeder, M. Martin, Cation self-diffusion of ${ }^{44} \mathrm{Ca},{ }^{88} \mathrm{Y}$, and ${ }^{96} \mathrm{Zr}$ in singlecrystalline calcia-and yttria-doped zirconia, Journal of applied physics 94(12) (2003) 75477552.

[48] J.R. Kelly, I. Denry, Stabilized zirconia as a structural ceramic: An overview, Dental Materials 24(3) (2008) 289-298.

[49] R.C. Garvie, P.S. Nicholson, Structure and thermomechanical properties of partially stabilized zirconia in the $\mathrm{CaO}-\mathrm{ZrO}_{2}$ system, Journal of the American Ceramic Society 55(3) (1972) 152-157.

[50] J.C. Ray, A.B. Panda, C.R. Saha, P. Pramanik, Synthesis of niobium(v)-stabilized tetragonal zirconia nanocrystalline powders, Journal of the American Ceramic Society 86(3) (2003) 514-516.

[51] F. Baxter, A. Garner, M. Topping, H. Hulme, M. Preuss, P. Frankel, Phase stability of zirconium oxide films during focused ion beam milling, Journal of Nuclear Materials 504 (2018) 176-180.

[52] F. Hofmann, R.J. Harder, W. Liu, Y. Liu, I.K. Robinson, Y. Zayachuk, Glancing-incidence focussed ion beam milling: A coherent $X$-ray diffraction study of 3D nano-scale lattice strains and crystal defects, Acta Materialia 154 (2018) 113-123. 
[53] J. Liu, S. Lozano-Perez, A.J. Wilkinson, C.R.M. Grovenor, On the depth resolution of transmission Kikuchi diffraction (TKD) analysis, Ultramicroscopy 205 (2019) 5-12.

[54] G. He, J. Liu, K. Li, J. Hu, A.H. Mir, S. Lozano-Perez, C. Grovenor, Investigating the stability of second phase particles in $\mathrm{Zr}$-Nb alloys under irradiation, Journal of Nuclear Materials 526 (2019) 151738.

[55] G. Greaves, A.H. Mir, R.W. Harrison, M.A. Tunes, S.E. Donnelly, J.A. Hinks, New Microscope and Ion Accelerators for Materials Investigations (MIAMI-2) system at the University of Huddersfield, Nuclear Instruments and Methods in Physics Research Section A: Accelerators, Spectrometers, Detectors and Associated Equipment 931 (2019) 37-43.

[56] J.F. Ziegler, M.D. Ziegler, J.P. Biersack, SRIM - The stopping and range of ions in matter (2010), Nuclear Instruments and Methods in Physics Research Section B: Beam Interactions with Materials and Atoms 268(11) (2010) 1818-1823.

[57] J.-M. Costantini, F. Beuneu, Threshold displacement energy in yttria-stabilized zirconia, Physica Status Solidi (c) 4(3) (2007) 1258-1263.

[58] M. Tonks, D. Andersson, R. Devanathan, R. Dubourg, A. El-Azab, M. Freyss, F. Iglesias, K. Kulacsy, G. Pastore, S.R. Phillpot, M. Welland, Unit mechanisms of fission gas release:

Current understanding and future needs, Journal of Nuclear Materials 504 (2018) 300-317.

[59] H.R. Faust, Z. Bao, Higher moments in the kinetic energy distribution of fission products, Nuclear Physics A 736(1) (2004) 55-76.

[60] M.L. Jenkins, M.A. Kirk, Characterisation of Radiation Damage by Transmission Electron Microscopy, CRC Press 2000.

[61] H. Yuan, E. Brodu, C. Chen, E. Bouzy, J.J. Fundenberger, L.S. Toth, On-axis versus off-axis Transmission Kikuchi Diffraction technique: application to the characterisation of severe plastic deformation-induced ultrafine-grained microstructures, Journal of Microscopy 267(1) (2017) 70-80.

[62] J. Liu, H. Yu, P. Karamched, J. Hu, G. He, D. Goran, G.M. Hughes, A.J. Wilkinson, S. Lozano-Perez, C.R.M. Grovenor, Mechanism of the $\alpha-Z r$ to hexagonal-ZrO transformation and its impact on the corrosion performance of nuclear Zr Alloys, Acta Materialia 179 (2019) 328-341.

[63] J. Liu, S. Lozano-Perez, P. Karamched, J. Holter, A.J. Wilkinson, C.R.M. Grovenor, Forescattered electron imaging of nanoparticles in scanning electron microscopy, Materials Characterization 155 (2019) 109814.

[64] T. Malis, S.C. Cheng, R.F. Egerton, EELS log-ratio technique for specimen-thickness measurement in the TEM, Journal of electron microscopy technique 8(2) (1988) 193-200. [65] H. Yang, J.G. Lozano, T.J. Pennycook, L. Jones, P.B. Hirsch, P.D. Nellist, Imaging screw dislocations at atomic resolution by aberration-corrected electron optical sectioning, Nature Communications 6(1) (2015) 7266.

[66] P.D. Nellist, S.J. Pennycook, The principles and interpretation of annular dark-field Zcontrast imaging, in: P.W. Hawkes (Ed.), Advances in Imaging and Electron Physics, Elsevier 2000, pp. 147-203.

[67] O.L. Krivanek, M.F. Chisholm, V. Nicolosi, T.J. Pennycook, G.J. Corbin, N. Dellby, M.F. Murfitt, C.S. Own, Z.S. Szilagyi, M.P. Oxley, S.T. Pantelides, S.J. Pennycook, Atom-by-atom structural and chemical analysis by annular dark-field electron microscopy, Nature 464(7288) (2010) 571-574.

[68] M.J. Hÿtch, E. Snoeck, R. Kilaas, Quantitative measurement of displacement and strain fields from HREM micrographs, Ultramicroscopy 74(3) (1998) 131-146. 
[69] A. Garner, F. Baxter, P. Frankel, M. Topping, A. Harte, T. Slater, P. Tejland, J.E. Romero, E.C. Darby, A. Cole-Baker, M. Gass, M. Preuss, investigating the effect of zirconium oxide microstructure on corrosion performance: a comparison between neutron, proton, and nonirradiated oxides, in: R. Comstock, A. Motta (Eds.), ASTM International, West Conshohocken, PA, 2018, pp. 491-523.

[70] S. Abolhassani, R. Restani, T. Rebac, F. Groeschel, W. Hoffelner, G. Bart, W. Goll, F. Aeschbach, TEM examinations of the metal-oxide interface of zirconium based alloys irradiated in a pressurized water reactor, Zirconium in the Nuclear Industry: Fourteenth International Symposium, ASTM International, 2005, 467-493.

[71] A. Garner, A. Gholinia, P. Frankel, M. Gass, I. MacLaren, M. Preuss, The microstructure and microtexture of zirconium oxide films studied by transmission electron backscatter diffraction and automated crystal orientation mapping with transmission electron microscopy, Acta Materialia 80 (2014) 159-171.

[72] D.R. Mitchell, DiffTools: Electron diffraction software tools for DigitalMicrograph ${ }^{\mathrm{TM}}$, Microscopy research and technique 71(8) (2008) 588-593.

[73] C. Howard, R. Hill, B. Reichert, Structures of ZrO2 polymorphs at room temperature by high - resolution neutron powder diffraction, Acta Crystallographica Section B 44(2) (1988) 116-120.

[74] E.F. Rauch, M. Véron, Crystal Orientation Angular Resolution with Precession Electron Diffraction, Microscopy and Microanalysis 22(S3) (2016) 500-501.

[75] H. Yu, J. Liu, P. Karamched, A.J. Wilkinson, F. Hofmann, Mapping the full lattice strain tensor of a single dislocation by high angular resolution transmission Kikuchi diffraction (HRTKD), Scripta Materialia 164 (2019) 36-41.

[76] H. Swan, M.S. Blackmur, J.M. Hyde, A. Laferrere, S.R. Ortner, P.D. Styman, C. Staines, M. Gass, H. Hulme, A. Cole-Baker, P. Frankel, The measurement of stress and phase fraction distributions in pre and post-transition Zircaloy oxides using nano-beam synchrotron X-ray diffraction, Journal of Nuclear Materials 479 (2016) 559-575.

[77] A. Garner, J. Hu, A. Harte, P. Frankel, C. Grovenor, S. Lozano-Perez, M. Preuss, The effect of Sn concentration on oxide texture and microstructure formation in zirconium alloys, Acta Materialia 99 (2015) 259-272.

[78] C. Cayron, T. Douillard, A. Sibil, G. Fantozzi, S. Sao - Jao, Reconstruction of the cubic and tetragonal parent grains from electron backscatter diffraction maps of monoclinic zirconia, Journal of the American Ceramic Society 93(9) (2010) 2541-2544.

[79] S.J. Zinkle, V.A. Skuratov, Track formation and dislocation loop interaction in spinel irradiated with swift heavy ions, Nuclear Instruments and Methods in Physics Research Section B: Beam Interactions with Materials and Atoms 141(1) (1998) 737-746.

[80] X. Zhang, K. Hattar, Y. Chen, L. Shao, J. Li, C. Sun, K. Yu, N. Li, M.L. Taheri, H. Wang, J. Wang, M. Nastasi, Radiation damage in nanostructured materials, Progress in Materials Science 96 (2018) 217-321.

[81] M. Fell, S.M. Murphy, The nucleation and growth of gas bubbles in irradiated metals, Journal of Nuclear Materials 172(1) (1990) 1-12.

[82] J. Barthel, Dr. Probe: A software for high-resolution STEM image simulation, Ultramicroscopy 193 (2018) 1-11.

[83] A. Kenich, M.R. Wenman, R.W. Grimes, lodine defect energies and equilibria in $\mathrm{ZrO}_{2}$, Journal of Nuclear Materials 511 (2018) 390-395. 
[84] J. Chevalier, L. Gremillard, A.V. Virkar, D.R. Clarke, the tetragonal-monoclinic transformation in zirconia: lessons learned and future trends, Journal of the American Ceramic Society 92(9) (2009) 1901-1920.

[85] G. Witz, V. Shklover, W. Steurer, S. Bachegowda, H.-P. Bossmann, phase evolution in yttria-stabilized zirconia thermal barrier coatings studied by rietveld refinement of X-ray powder diffraction patterns, Journal of the American Ceramic Society 90(9) (2007) 29352940.

[86] G.M. Wolten, Direct high-temperature single-crystal observation of orientation relationship in zirconia phase transformation, Acta Crystallographica 17(6) (1964) 763-765. [87] T.-S. Sheu, T.-Y. Tien, I.-W. Chen, Cubic-to-Tetragonal (t') Transformation in ZirconiaContaining Systems, Journal of the American Ceramic Society 75(5) (1992) 1108-1116. [88] P.M. Kelly, L.R. Francis Rose, The martensitic transformation in ceramics - its role in transformation toughening, Progress in Materials Science 47(5) (2002) 463-557.

[89] M. Freyss, T. Petit, J.-P. Crocombette, Point defects in uranium dioxide: Ab initio pseudopotential approach in the generalized gradient approximation, Journal of Nuclear Materials 347(1) (2005) 44-51.

[90] O.I. Malyi, P. Wu, V.V. Kulish, K. Bai, Z. Chen, Formation and migration of oxygen and zirconium vacancies in cubic zirconia and zirconium oxysulfide, Solid State Ionics 212 (2012) 117-122.

[91] D.S. Aidhy, B. Liu, Y. Zhang, W.J. Weber, Chemical expansion affected oxygen vacancy stability in different oxide structures from first principles calculations, Computational Materials Science 99 (2015) 298-305.

[92] Y.R. Lin, L.G. Chen, C.Y. Hsieh, M.T. Chang, K.Y. Fung, A. Hu, S.C. Lo, F.R. Chen, J.J. Kai, Atomic Configuration of Point Defect Clusters in Ion-Irradiated Silicon Carbide, Scientific Reports 7(1) (2017) 14635.

[93] V. Shishov, M. Peregud, A. Nikulina, Y.V. Pimenov, G. Kobylyansky, A. Novoselov, Z. Ostrovsky, A. Obukhov, Influence of structure-Phase state of $\mathrm{Nb}$ containing $\mathrm{Zr}$ alloys on irradiation-induced growth, Zirconium in the Nuclear Industry: Fourteenth International Symposium, ASTM International, 2005, 666-685.

[94] K. Edsinger, K.L. Murty, LWR pellet-cladding interactions: Materials solutions to SCC, JOM 53(7) (2001) 9-13.

[95] T. G. Lach, D.J. Edwards, E.C. Buck, B.K. McNamara, J.M. Schwantes, R.A. Clark, Fission recoil-induced microstructural evolution of the fuel-cladding interface $[\mathrm{FCl}]$ in high burnup BWR fuel, Journal of Nuclear Materials 521 (2019) 120-125.

[96] C. Ciszak, M. Mermoux, S. Miro, G. Gutierrez, F. Lepretre, I. Popa, K. Hanifi, I. ZacharieAubrun, L. Fayette, S. Chevalier, Micro-Raman analysis of the fuel-cladding interface in a high burnup PWR fuel rod, Journal of Nuclear Materials 495 (2017) 392-404.

[97] A. Couet, L. Borrel, J. Liu, J. Hu, C. Grovenor, An integrated modeling and experimental approach to study hydrogen pickup mechanism in zirconium alloys, Corrosion Science (2019) 108134. 